\title{
Mismatch on the Dutch labour market in the Great Recession
}

Hugo Erken

Eric van Loon

Wouter Verbeek 



\title{
Mismatch on the Dutch labour market in the Great Recession
}

\author{
Hugo Erken*, Eric van Loon, and Wouter Verbeek \\ CPB Netherlands Bureau for Policy Analysis, P.O. Box 80510, 2508 GM, The Hague
}

\begin{abstract}
The Great Recession has caused unemployment in the Netherlands to rise from 3.1\% in 2008 to over 7\% at the beginning of 2014. Structural imbalances caused by labour mismatch could be one of the explanations underlying this high rate. The goal of this paper is to examine this hypothesis. We adopt an eclectic approach to study if mismatch has increased during the Great Recession. First, we examine the development of the Beveridge curve. We estimate so-called "steady-state" Beveridge curves based on underlying labour market flows. Outward shifts of these curves are associated with decreasing matching efficiency. Second, we construct a mismatch index which enables us to calculate the contribution of sector mismatch to the unemployment level. Our analyses show little support for the hypothesis that mismatch currently is a problem on the Dutch labour market. At the aggregate level, the Beveridge curve has not shifted outwards. Furthermore, at most one-seventh of Dutch unemployment can be attributed to sector mismatch, which is comparable to or below periods prior to the Great Recession.
\end{abstract}

JEL classification: E20, E24, J63, J69

Keywords: Beveridge curve, mismatch, labour market, unemployment, vacancies, Great Recession

* Corresponding author: h.p.g.erken@cpb.nl. The views in this article are those of the authors and do not necessarily reflect the policy or position of the CPB. We would like to thank Rob Vlek and Marcia Kantoor from UWV, as well as Statistics Netherlands for customised data deliverance. In addition, we thank Jan van Ours, Pieter Gautier, Bas ter Weel, Daniel van Vuuren, Adam Elbourne, Marloes de Graaf-Zijl and Pieter van Winden for useful comments on earlier versions of this paper. This paper was presented at the Netherlands Economist Day 2014, the Ministry of Economic Affairs and the Ministry of Social Affairs and Employment. 


\section{Introduction}

High unemployment can reflect cyclical developments such as a shortfall in aggregate demand, but can also be the result of structural factors such as increasing matching frictions. For the United States, the cyclical versus the structural explanation of unemployment is debated intensely in the literature (cf. Hobijn and Şahin, 2013; Daly et al., 2012; Dickens and Triest, 2012; Şahin et al., 2014; Lazear and Spletzer, 2012; Rothstein, 2012; Valletta and Kuang, 2010). Such a debate is lacking for the Dutch unemployment situation and even for Europe in general (Arpaia et al., 2014). In this study, we try to partly fill this gap by examining mismatch on the Dutch labour market, using methodologies from the US literature. The contribution of this paper to the literature is threefold. First, we adopt an eclectic approach to study mismatch. We examine shifts of the Beveridge curve relation between vacancies and unemployment on the macro level and within 28 industries. In addition, we study the allocation of unemployment and vacancies across sectors, which enables us to measure the contribution of sector mismatch. Our second contribution is that we have developed a new method to formally test for a break in series between the pre-crisis and crisis steady-state Beveridge curve to see whether a shift has occurred. The method is based on bootstrapping methodology. Third and finally, we introduce a new way to measure mismatch during recovery periods, by deriving an expected recovery path along the Beveridge curve.

Mismatch refers to a poor match between labour supply and labour demand, which is reflected by the coexistence of high unemployment and a large number of job openings or vacancies. If mismatch persists over a long period of time, it can result in erosion of human capital (Ball, 2009), long unemployment spells and extensive periods of jobless recovery (Groshen and Potter, 2003). Mismatch can occur for several reasons. First, technological shocks can cause occupations or sectors that use conventional knowledge and skills to disappear, whilst creating new occupations and sectors that require new technology-specific skills (see, e.g., Bauer and Bender, 2004; Michaels et al., 2014; Goldin and Katz, 2008). Slow wage adjustments and immobile labour can exacerbate occupational and sector mismatch (Jackman and Roper, 1987). In addition, mismatch often becomes a problem in the aftermath of a recession, as employers use economic downturns as an opportunity to restructure their firm due to relatively low opportunity costs (see Caballero and Hammour, 1994; Davis and Haltiwanger, 1990; Koenders and Rogerson, 2005; Katz, 2010). Second, when the unemployed are not situated near available jobs, so-called geographical mismatch can become a problem. ${ }^{1}$ This type of mismatch finds its roots in, e.g., the relocation of business activities or regional differences in employment growth. Third, and finally, a decline in matching efficiency can be the result of labour market institutions, such as generous unemployment benefits or low entry conditions for disability schemes. Higher duration, coverage and level of unemployment benefits negatively affect the readiness of the unemployed to search for jobs (e.g. Rothstein, 2011; Nickell et al., 2003).

Figure 1 puts mismatch on the Dutch labour market in a historical perspective by illustrating the Beveridge curve during four economic cycles. The Beveridge curve is widely used as a tool to separate cyclical from structural shocks on the labour market and hence analyse the potential increase of mismatch (see Elsby et al. (forthcoming) for an overview). The economic dip of the 1990s and the dotcom-crisis both show an anti-clockwise adjustment pattern along a convex curve, with almost identical values at the beginning and end of the cycle. This indicates that the deterioration on the Dutch labour market was primarily cyclical in nature, rather than structural. The recession of the 1980 s, however, is a different case in point. Figure 1 shows a clear outward shift of the Beveridge curve during this recession. Typically, an outward shift of the Beveridge curve is associated with deteriorating matching efficiency, implying that more vacancies are needed to keep unemployment at a given level. These changes are linked to the efficiency of workers-to-jobs-matches and will negatively affect labour allocation throughout the economy. This is exactly what happened in the Netherlands in the 80s: the matching efficiency deteriorated due to structural supply-side problems related to incentive and motivation (OECD, 1993).2,3

\footnotetext{
${ }^{1}$ Geographical mismatch can be exacerbated by so-called "house lock", which means that the unemployed cannot move to regions with expanding employment because their housing debt exceeds the market value of their home (Sterk, 2010). In general, the literature finds limited evidence for house lock causing geographical mismatch (cf. Valletta, 2013; Aaronson and Davis, 2011; Donovan and Schnure, 2011; Modestino and Dennett, 2013).

${ }^{2}$ During the 1980s, some employers had difficulties filling low-skilled jobs, whereas unemployment among low-skilled was high as well. The OECD (1993) argues that this situation was the result of the Dutch level of replacement rates during the 80s, which were among the highest of the OECD for all types of family situations and for all unemployment spells.

${ }^{3}$ Evidence of an outward shift due to higher long-term unemployment is also reported by Driehuis (1990). However, the outward shift of the Beveridge curve was relatively short-lived and followed by an inward shift during the 1990s (Van Ours, 2003; Bouvet, 2012). This inward shift, most likely, was the result of improvements in matching efficiency in the Netherlands, particularly due to reforms of the unemployment benefits system in the Netherlands, which became less generous (Nickell and Van Ours, 2000).
} 
Figure 1 also illustrates the development of the Beveridge curve during the phase of stagnation up till 2013. The main question is how the Beveridge will develop in the recovery phase, which roughly started at the beginning of 2014. Will the curve move back to its initial position or can we expect an outward shift of the curve, as witnessed in the 1980s? One possible reason to expect an outward shift is that mismatch seems to be more prominent in countries - e.g. Portugal, the United Kingdom, the United States and Spain - that experienced housing busts and substantial losses of employment in the construction sector (Hobijn and Şahin 2013; Bonthuis et al. 2012). ${ }^{4}$ The Dutch case fits into this category: since the peak of the market (late 2008), real house prices in the Netherlands have declined by almost 30\% (CPB, 2014). As a consequence, employment in the construction sector dropped by 16 percent between the last quarter of 2008 and the first quarter of 2014 (against -2.2 percent for total employment).

\section{Figure 1. The Beveridge curve in the Netherlands during four downturns}
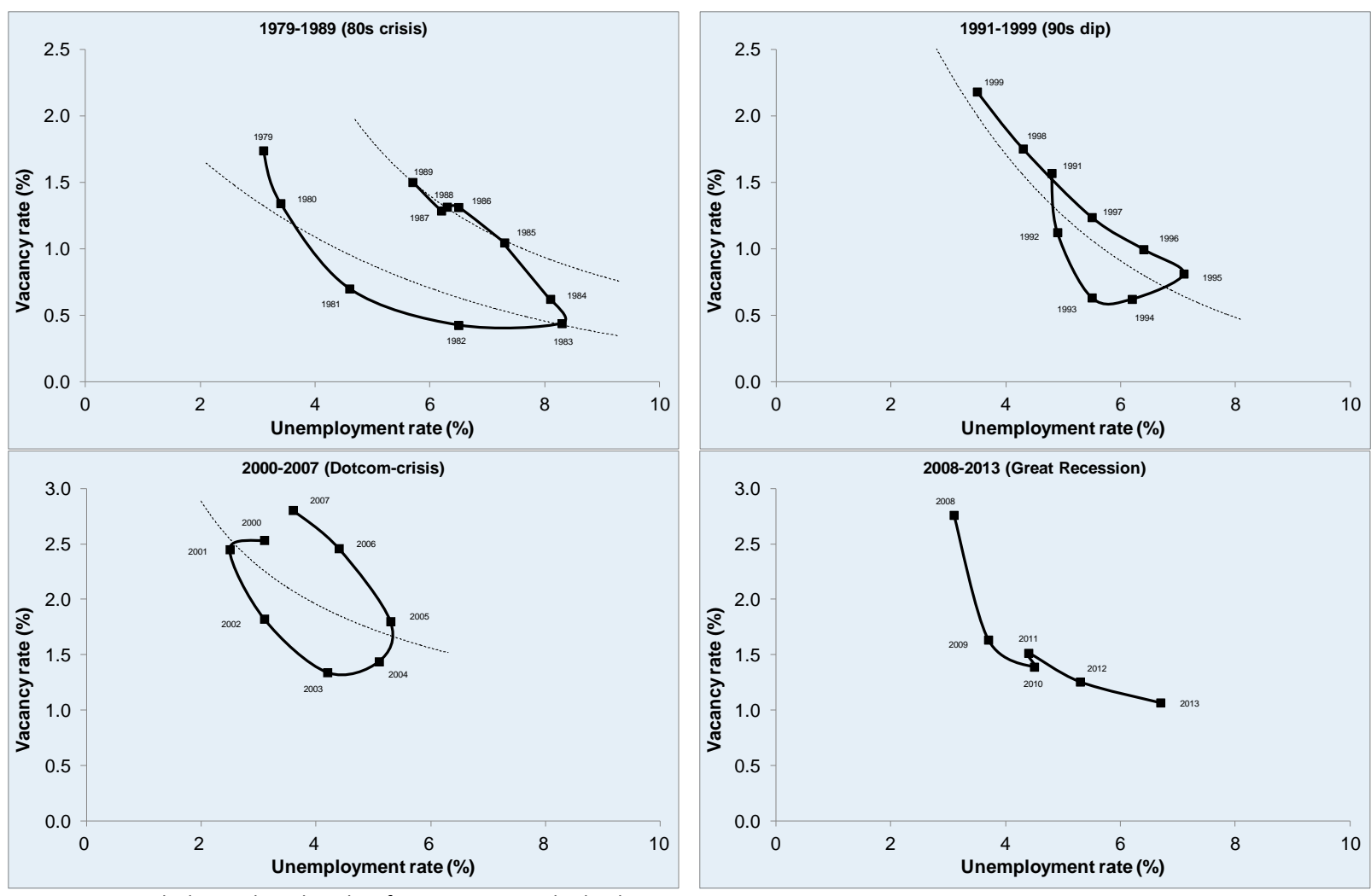

Source: own calculations based on data from Statistics Netherlands.

Explanation: Unemployment and the labour force according to the ILO-definition. Each economic cycle starts one year after the peak in GDP growth and ends on the subsequent peak. We follow Blanchard and Diamond (1989), Petrongolo and Pissarides (2001) and Elsby et al. (forthcoming) by defining the vacancy rate $(v)$ as the number of vacancies $(V)$ as a fraction of the total labour force $(L): v=V / L$. The unemployment rate $(u)$ is defined as the total number of unemployed $(U)$ as a fraction of the labour force $(L): U=U / L$.

In order to detect outward shifts of the Beveridge curve during the Great Recession, we follow a number of studies (i.e. Barnichon and Figura, 2011; Şahin et al., 2014; Hobijn and Şahin, 2013) and estimate a "steady-state" Beveridge curve. This is done by linking labour market flows to a matching function using pre-recession data. Next, we compare the steady-state curve to observations after the start of the Great Recession in 2008. Large deviations from our steady-state curve are an indication of mismatch. We also formally test for a shift of the curve by examining whether there is a break between the pre-crisis and crisis curve. The use of labour market flows to derive a steady-state Beveridge curve enables us to identify the drivers of a possible outward shift. However, in our study we find no evidence that the curve has shifted outwards; actual observations lie close to the steady-state Beveridge curve. Our structural break analysis does not provide support for an outward shift as well. Therefore, from a macro perspective, we

\footnotetext{
${ }^{4}$ Although the housing bust seems to be the common factor behind the observed increase in mismatch in several countries due to the Great Recession, the labour market response was substantially different between countries, as is the expected permanency of the damage inflicted. In the US, there is much consensus between economists that the observed mismatch is mainly transitory in nature rather than structural. At the other end of the spectrum, the source of the strong mismatch in Spain relates to a core problem on the Spanish labour market, being the pronounce insideroutsider divide (see Bentolila et al., 2012a,b). This enhances the risk that the high cyclical unemployment in Spain is becoming entrenched as a permanent rise (OECD, 2012).
} 
find no indications that the Beveridge curve has shifted outwards and mismatch currently is a considerable problem on the Dutch labour market. These conclusion are in line with results found earlier for the Netherlands by Hobijn and Şahin (2013), the European Commission (2013), and Arpaia et al. (2014). By estimating matching functions for the Dutch labour market, our paper is also related to the literature that examines matching efficiency on the Dutch labour market (see, for instance, Van Ours (1991) and Broersma and Van Ours (1999)).

Besides measuring shifts of the Beveridge curve, we also examine sector mismatch by calculating a mismatch index, based on Şahin et al. (2014). This index compares the actual distribution of the unemployed across sectors to an optimal allocation set by a fictitious "planner", who can move unemployed workers across sectors without restrictions. When moving the unemployed, the planner looks at sector differences in labour market tightness and sector-specific matching efficiencies. Our index is estimated for the period 2000-2014 and shows that at most $18 \%$ of the current unemployment level can be attributed to sector mismatch. This estimate is low when compared to its own time series and to findings for other countries. Şahin et al. (2014) find that mismatch across industries explains up to onethird of the total observed increase of the unemployment rate in the United States. A similar estimate is found by Marthin (2013) for Sweden. Shibata (2013) shows that occupational mismatch (which is closely related to sector mismatch) explains roughly 20 to $40 \%$ of the unemployment increase in Japan during the Great Recession.

The remainder of this paper is structured as follows. In Section 2, we introduce a framework to analyse mismatch using the Beveridge curve and the mismatch index. Section 3 describes the data. In Section 4, we present the results of our analyses. Section 5 concludes.

\section{Conceptual framework}

This section introduces our framework to analyse mismatch on the Dutch labour market. In Section 2.1 we will explain the estimation of our steady-state Beveridge curve based on a three-state labour market model. ${ }^{5}$ In Section 2.2 we will elucidate on the measurement of sector mismatch by introducing a mismatch index.

\subsection{Deriving the steady-state Beveridge curve}

It is possible to derive a steady-state Beveridge curve using a model with three labour market states: unemployment $(U)$, employment $(E)$ and non-participation $(N)$ (see Barnichon et al., 2012). The first step is to define our steady-state condition: the unemployment rate is in its steady state when the growth rate of the labour force, which we denote by $g_{t}^{(l f)}$, equals the growth rate of employment, denoted by $g_{t}^{(e)}$. To derive a Beveridge curve from this steady-state condition, we have to relate these growth rates to the vacancy and unemployment rates. We do so by considering the gross labour market flows that underlie these growth rates. First of all, we write:

$g_{t}^{(l f)}=\eta_{t}-\chi_{t}$

in which $\eta_{t}$ is the number of people entering the labour market during period $t$ as a fraction of the number of people in the labour force at the beginning of period $t$ and $\chi_{t}$ representing the number of people who exit the labour force during period $t$ divided by the number of people in the labour force at the beginning of period $t$.

Secondly, the growth rate of employment, $g_{t}(e)$, equals the hiring rate $h_{t}$ during period $t$ minus the separation rate, $s_{t}$. The separation rate is defined as all separations (i.e. quits and layoffs) during a period as a fraction of the employed labour force at the beginning of the period. We follow Barnichon et al. (2012), Hobijn and Şahin (2013), Davis et al. (2010) and Sedláček (2014) by expressing the hiring rate, $h_{t}$, as the number of hires per vacancy, or the vacancy yield. The vacancy yield is calculated as the flow of realised hires during period $t$ as a fraction of the reported vacancies at the beginning of period $t$.

Next, we can derive the following employment growth-rate equation (see Appendix A.1):

\footnotetext{
${ }^{5}$ Elsby et al. (forthcoming) discuss several features that are omitted from the baseline search model that we use, such as wage determination, entry costs or the anti-cyclicality of search intensity. We take notice of the drawbacks of our model; however, it is not the purpose of this paper to amend any of these suggestions and future research is needed to make such refinements.
} 
$g_{t}^{(e)}=\frac{\frac{v_{t}}{1-v_{t}} h_{t}-s_{t}}{1-\frac{v_{t}}{1-v_{t}} h_{t}+s_{t}}$

where $v_{t}$ is defined as the number of vacancies at the beginning of period $t$ as a ratio of the labour force at the beginning of period $t$.

Our next step is to link our hire rate to the $v_{t} / u_{t}$-ratio, which captures labour market tightness. In economic upswings, the $v_{t} / u_{t}$-ratio will be high, increasing the chances for the unemployed to be hired and reducing the chances of the employed to be laid off. Therefore, the $v_{t} / u_{t}$-ratio captures the cyclical movements in the hire rate. We follow the search and matching literature (cf. Petrongolo and Pissarides, 2001; Mortensen and Pissarides, 1994; Shimer, 2005) and assume that the number of newly-hired workers $\left(M_{t}\right)$ can be explained by a constant returns to scale Cobb-Douglas matching function depending on the number of unemployed workers $(U)$ and the number of vacancies $(V)$ (e.g. Pissarides, 2001; Veracierto; 2011; Barnichon, 2012):

$M_{t}=\beta^{M} U_{t}^{\alpha^{M}} V_{t}^{1-\alpha^{M}}$

where $0<\alpha^{M}<1$. Parameter $\alpha^{M}$ is the output elasticity relating the number of vacancies and unemployed to the amount of newly hired workers. $\beta^{M}$ accounts for factors unrelated to the number of vacancies and the number of unemployed. The probability that the average vacancy is filled is given by the hire rate:

$$
\begin{aligned}
& h_{t}=\frac{M_{t}}{V_{t}}=\beta^{M} U_{t}^{\alpha^{M}} V_{t}^{1-\alpha^{M}} V_{t}^{-1}=\beta^{M}\left(\frac{U_{t}}{V_{t}}\right)^{\alpha^{M}}=\beta^{M}\left(\frac{\frac{U_{t}}{L_{t}}}{V_{t}}\right)^{\alpha^{M}} \\
& =\beta^{M}\left(\frac{u_{t}}{v_{t}}\right)^{\alpha^{M}}=\beta^{M}\left(\frac{v_{t}}{u_{t}}\right)^{-\alpha^{M}}=\beta^{M}\left(\frac{v_{t}}{u_{t}}\right)^{\alpha^{h}}
\end{aligned}
$$

with $M_{t}$ being the number of new matches and $V_{t}$ the number of vacancies. Following Barnichon (2012), the hire rate can be estimated by taking natural logs of the matching function:

$\ln \left(h_{t}\right)=\ln \beta^{M}+\alpha^{h} \ln \left(\frac{v_{t}}{u_{t}}\right)+\varepsilon_{t}=\beta^{h}+\alpha^{h} \ln \left(\frac{v_{t}}{u_{t}}\right)+\varepsilon_{t}$

where $\varepsilon_{t}$ denotes a normally-distributed error term.

Shimer (2005) argues that the separation rate is not related to cyclical movements and does not contribute much to unemployment fluctuations. Therefore, the literature on steady-state Beveridge curves typically treats the separation rate as constant (e.g. Hall, 2005). However, there is an emerging body of research demonstrating that the separation rate moves anti-cyclically (e.g. Elsby et al., 2009; Fujita and Ramey, 2009; Smith, 2011). Moreover, Van Loon et al. (2014) show that the separation rate can explain approximately 40 percent of unemployment variation in the Netherlands. We treat the separation rate $\left(s_{t}\right)$ in a similar way as the hire rate by using a Cobb-Douglas function relating it to the $v_{t} / u_{t}$-ratio (Hobijn and Şahin, 2012):

$\ln \left(s_{t}\right)=\beta^{s}+\alpha^{s} \ln \left(\frac{v_{t}}{u_{t}}\right)+\varepsilon_{t}$

In a similar fashion, we link labour market inflow and outflow to our indicator for labour market tightness - the $v / u$-ratio - and estimate four gross flows that determine the growth rates of the labour force and employment (Barnichon et al., 2012). Thus, we estimate for $y_{t}=\eta_{t}, \chi_{t}, h_{t}, s_{t}$ :

$\ln \left(y_{t}\right)=\beta^{y}+\alpha^{y} \ln \left(\frac{v_{t}}{u_{t}}\right)+\varepsilon_{t}$ 
where $\varepsilon_{t}$ denotes a normally-distributed error term. The estimated parameters from the flow rate functions (equation 7) allow us to derive a steady-state equation. The steady-state Beveridge curve is defined as the implicit solution to:

$0=e^{\widehat{\beta}^{\eta}}\left(\frac{v_{t}}{u^{*}}\right)^{\widehat{\alpha}^{\eta}}-e^{\widehat{\beta}^{\chi}}\left(\frac{v_{t}}{u^{*}}\right)^{\hat{\alpha}^{\chi}}-\frac{\frac{v_{t}}{1-v_{t}} e^{\widehat{\beta}^{h}}\left(\frac{v_{t}}{u^{*}}\right)^{\widehat{\alpha}^{h}}-e^{\widehat{\beta}^{s}}\left(\frac{v_{t}}{u^{*}}\right)^{\widehat{\alpha}^{s}}}{1-\frac{v_{t}}{1-v_{t}} e^{\widehat{\beta}^{h}}\left(\frac{v_{t}}{u^{*}}\right)^{\widehat{\alpha}^{h}}+e^{\widehat{\beta}^{s}}\left(\frac{v_{t}}{u^{*}}\right)^{\widehat{\alpha}^{s}}}$

The derivation of equation (8) is shown in Appendix A.2. Equation (8) can be used to calculate the steadystate levels for the unemployment rate $\left(u^{*}\right)$, given the vacancy rate $\left(v_{t}\right)$. This steady-state unemployment rate is defined as the rate for which employment growth equals the growth of the labour force. These growth rates are, subsequently, determined by the estimated flow rate equations. Since equation (8) has no explicit solution, the steady-state Beveridge curve is determined by solving equation (8) for $u^{*}$ at different points of $v_{t}$. Figure A.4 in Appendix A.10 shows that unemployment dynamics are accurately approximated by steady-state value of our three-state labour market model. This model is used to estimate the Beveridge curve on the aggregate level in Section 4.1.

\subsection{Sector mismatch}

The aggregate perspective from the previous section might miss heterogeneity at the sector level. To make this point clear, suppose that during a recession there is a movement along the Beveridge curve and all new unemployed are located in sector X, whilst the decrease in vacancies takes place in sector Y (other sectors have no change in unemployment or vacancies). This extreme example would cause no outward shift of the Beveridge curve at the aggregate level, although mismatch between vacancies and unemployment has increased at the sector level. Therefore, we also need to examine mismatch between sectors. This refers to a labour market where the unemployed are not efficiently allocated towards the sectors where jobs are available, i.e. the unemployed search in the wrong sector. As a consequence, sector mismatch, if present, should manifest itself by a high spread in the sector $v_{t} / u_{t}$-ratios, i.e. high and low $v_{t} / u_{t}$-ratios within the economy co-exist (Jackman and Roper, 1987). In the extreme case of no mismatch, all $v_{t} / u_{t}$-ratios should be equal to the aggregate $v_{t} / u_{t}$-ratio and hence the spread would be zero. All sector mismatch indices in the literature take this idea as a starting point.

Canon et al. (2013) provide a useful review of eight mismatch indices that have been developed over time. The authors conclude that the index developed by Jackman and Roper (1987), and extended by Şahin et al. (2014), in particular stands out as the most practical and intuitive. Hence, in this section we will mainly focus on this specific mismatch index as our framework to examine sector mismatch. Şahin et al. (2014) describe the labour market as a set of submarkets differentiated by geography, sector and occupations. Hires in each of these submarkets can be modelled by a Cobb-Douglas matching function. Next, Şahin et al. (2014) define a benchmark situation where workers are optimally allocated across these submarkets (in our case: 28 sectors). This counterfactual situation is the one that would be chosen by a fictitious "planner" who can move unemployed workers across sectors freely. The planner moves the unemployed to sectors with a tight labour market and high matching efficiency until matching efficiency-weighted $v_{t} / u_{t}$-ratios are equal between sectors. To calculate the degree of mismatch, the actual number of hires $(H)$ is compared with the counterfactual number of hires achieved by the planner $\left(H^{*}\right)$. Any discrepancy between the two signifies sector mismatch. Ideally, we should not only estimate an index for sector mismatch, but also for occupational and regional mismatch. This is not possible due to data limitations, but we do calculate a simpler version for these types of mismatch later on in this section.

We assume that displaced workers look for work in sectors where they were previously occupied; network ties and sector-specific human capital induce the unemployed to look for jobs in their own sector. Searching for jobs in other sectors is also less attractive because of wage penalties (Deelen et al., 2014). Our assumption of course not always holds, as some occupations, such as receptionists or security guards, have a high sector mobility. However, administrative data on sector mobility show that nearly $60 \%$ of unemployment benefit recipients find work in the sector where they were previously active. This figure makes our assumption and the estimation of sector-specific matching functions quite reasonable. ${ }^{6}$

\footnotetext{
${ }^{6}$ Şahin et al. (2014) also show that the bulk of the unemployed find work in the sector in which they were previously active.
} 
The model

In order to apply the framework by Şahin et al. (2014) to the Dutch situation, we need to elaborate on some features of the model. The economy is divided into different labour markets or sectors denoted by $i$ $=\{1, \ldots, \mathrm{I}\}$. New production opportunities arise exogenously across sectors and correspond to job vacancies $\left(V_{i}\right)$. Risk-neutral individuals can be in two labour market states: employed in sector $i\left(E_{i}\right)$ or unemployed and searching in sector $i\left(U_{i}\right)$. Şahin et al. (2014) abstract from on-the-job search and the unemployed can only search for a job in one sector during a given period of time. Labour market frictions exist and the number of new hires in a sector $\left(H_{i}\right)$ is given by a matching function which uses the unemployed $\left(U_{i}\right)$ and vacancies $\left(V_{i}\right)$ as its inputs:

$H_{i}=\Phi \cdot \phi_{i} \cdot m\left(U_{i}, V_{i}\right)$

where $\Phi$ represents the matching efficiency of the whole economy and $\phi_{i}$ denotes the matching efficiency in sector $i$. Thus, total matching efficiency in sector $i$ is given by $\Phi \phi_{i}$. Next, $m$ is assumed to be strictly increasing and concave in both arguments and homogenous of degree one (constant returns to scale). Existing matches produce output $Z$ (homogenous sector productivity) and matches are destroyed exogenously at rate $s_{t}$ across all sectors. In the benchmark model, there are only two sources of heterogeneity across sectors: the number of vacancies $\left(V_{i}\right)$ and matching efficiency $\left(\phi_{i}\right)$.

The model dynamics work as follows. At the beginning of the period, aggregate shocks $(Z, \Delta, \Phi)$ and the distribution of $\phi_{i}$ and $V_{i}$ are observed. The distribution of active matches, $e=\left\{e_{1}, \ldots, e_{\mathrm{I}}\right\}$, across sectors is also given. Since the labour force is also given, unemployment at the start of the period is known $(U)$. Next, each unemployed agent chooses a labour market $i$, the matching process takes place and new hires are made in each market according to equation (9). Subsequently, production takes place in existing matches, $E_{i}$, and new matches $H_{i}$. Finally, a share $s_{t}$ of the matches is destroyed in each sector $i$, determining the distribution of employment $\left(E_{i}\right)$ and unemployment $\left(U^{\prime}\right)$ in the next period. Next, the planner's task is to allocate the unemployed workers across sectors in this economy, so that?

$\phi_{1} m_{u 1}\left(\frac{V_{1}}{U_{1}^{*}}\right)=\cdots=\phi_{i} m_{u i}\left(\frac{V_{i}}{U_{i}^{*}}\right)=\cdots=\phi_{i} m_{u I}\left(\frac{V_{I}}{U_{I}^{*}}\right)$

where $(*)$ denotes the planner's allocation. Equation (10) states that the planner allocates more job seekers to sectors with more vacancies and a higher matching efficiency. So the unemployed are reallocated towards sectors with a tight labour market and where vacancies and the unemployed are easily matched.

Following Petrongolo and Pissarides (2001), our matching function $m\left(V_{i}, U_{i}\right)$ per sector can be written as a Cobb-Douglas function:

$H_{i, t}=\Phi_{\mathrm{t}} \phi_{i} V_{i, t}^{\alpha} U_{i, t}^{1-\alpha}$

where $H$ expresses the amount of hires at time $t$ and $\alpha \in(0,1)$ is the vacancy share common across all sectors. Next, we can solve $U^{*}$ by substituting (10) in (11):

$U_{i, t}^{*}=\phi_{i}^{\frac{1}{\alpha}} \cdot \frac{V_{i, t}}{\sum_{i=1}^{I}\left(V_{i, t} \phi_{i}^{\frac{1}{\alpha}}\right)} U_{t}$

Equation (12) gives the optimal unemployment per sector. The optimal number of hires across all sectors can be written as:

$H_{t}^{*}=\Phi_{\mathrm{t}} V_{t}^{\alpha} U_{t}^{1-\alpha} \overline{\phi_{t}}$

with

\footnotetext{
${ }^{7}$ See Appendices A.1 and A.2 in Şahin et al. (2012) and Appendix A in Marthin (2012) for a detailed solution of the planner's problem.
} 
$\overline{\phi_{t}}=\left(\sum_{i=0}^{I} \phi_{i}^{\frac{1}{\alpha}}\left(\frac{V_{i, t}}{V_{t}}\right)\right)^{\alpha}$

The complete derivation of equations (12), (13) and (14) is reported in Appendix A.3.

\section{Mismatch index}

Mismatch describes the gap between the counterfactual amount of hires $\left(H^{*}\right)$ and the actual amount of hires $(H)$. Thus, our mismatch index $\left(M_{t}\right)$ reports the number of missed hires, expressed as a fraction of the counterfactual amount of hires $\left(H^{*}\right)$ :

$M_{t}=1-\frac{H_{t}}{H_{t}^{*}}=1-\sum_{i=0}^{I}\left(\frac{\phi_{i}}{\overline{\phi_{t}}}\right)\left(\frac{V_{i, t}}{V_{t}}\right)^{\alpha}\left(\frac{U_{i, t}}{U_{t}}\right)^{1-\alpha}$

The actual amount of hires $\left(H_{t}\right)$ is obtained by cumulating the sector-specific hires $H_{i, t}$. We obtain estimates for our model parameters by estimating the following panel regressions with both time-fixed and sector-fixed effects (Şahin et al., 2014; Marthin, 2012):

$\ln \left(\frac{H_{i, t}}{U_{i, t}}\right)=c+\ln \left(\Phi_{t}\right)+\ln \left(\varphi_{i}\right)+\alpha \ln \left(\frac{V_{i, t}}{U_{i, t}}\right)+\varepsilon_{t}$

The aggregate matching efficiency $\ln \left(\Phi_{t}\right)$ is estimated with time-fixed effects and will capture the timevarying effects that are constant between sectors. The sector-specific matching parameter $\ln \left(\varphi_{i}\right)$ is estimated by the sector-fixed effects, which captures sector heterogeneity that is constant over time. The elasticity $\alpha$ describes the effect of a percentage change in the $V_{i, t} / U_{i, t}$-ratio (i.e. the change in labour market tightness) on the percentage change in hires per unemployed, when all sector and time-fixed effects have been controlled for.

\section{Contribution mismatch to unemployment}

The mismatch index can be used to compute the contribution of mismatch to unemployment. The basic idea developed by Şahin et al. (2014) is to compare the actual development of unemployment with a counterfactual level of unemployment. This counterfactual level reflects the allocation of the unemployed across sectors in the absence of mismatch, taking into account differences in matching efficiencies and in labour market tightness. To see how this works, we start by defining the job-finding rate as follows:

$f_{t}=\frac{H_{t}}{U_{t}}=\left(1-M_{t}\right) \Phi_{t} \overline{\phi_{t}}\left(\frac{V_{t}}{U_{t}}\right)$

Next, the counterfactual job-finding rate in a world without mismatch (i.e. $M_{t}=0$ ) is given by:

$f_{t}^{*}=\frac{H_{t}^{*}}{U_{t}^{*}}=\Phi_{t} \overline{\phi_{t}}\left(\frac{V_{t}}{U_{t}^{*}}\right)$

Using the counterfactual job-finding rate $\left(f_{t}^{*}\right)$, we can calculate the counterfactual level of unemployment $\left(U^{*}\right)$ that would exist without mismatch. ${ }^{8}$ Changes in unemployment can be expressed using the following equation:

$U_{t+1}^{*}=s_{t}\left(E_{t}+\left(U_{t}-U_{t}^{*}\right)\right)+f_{t}^{*} U_{t}^{*}$

Given an initial value of $U_{0}^{*}$, this equation can be iterated forward to obtain a path of the counterfactual unemployment without mismatch. When iterating equation (19) forward, we take the paths of $s_{t}$ and $V_{t}$ as given, because the separation rate and the number of vacancies are exogenous to the planner. The difference between $U_{t}$ and $U_{t}^{*}$ is then labelled as that part of unemployment due to mismatch.

\footnotetext{
${ }^{8}$ In contrast to Şahin et al. (2014), we use the unemployment level rather than the unemployed rate.
} 


\section{Data}

\section{Macro data}

In order to derive our macro steady state Beveridge curve, we use quarterly data from the Labour Force Survey (LFS) of Statistics Netherlands on labour market flows covering the period 2003 to 2013. These series encompass the flows out and into the labour force and flows in and out of employment and unemployment during a quarter (see Figure 2). We use a Census X12-filter to adjust the labour market flows data for seasonal effects. ${ }^{9}$ The definitions of the labour force, employed labour force, and unemployment in our data differ somewhat from the international ILO-definition regarding these variables. ${ }^{10}$

Quarterly data on the number of vacancies are also taken from Statistics Netherlands. As the vacancy data represent quarterly ultimo figures and the LFS data on labour market stocks encompass monthly averages, we average two seasonally-adjusted months to get ultimo figures for the labour force, the employed labour force and unemployment for each quarter, e.g. ultimo first quarter is the average of the months March and April. In this way, we compute time-consistent $v_{t} / u_{t}$-ratios.

\section{Figure 2. Labour market flow data}

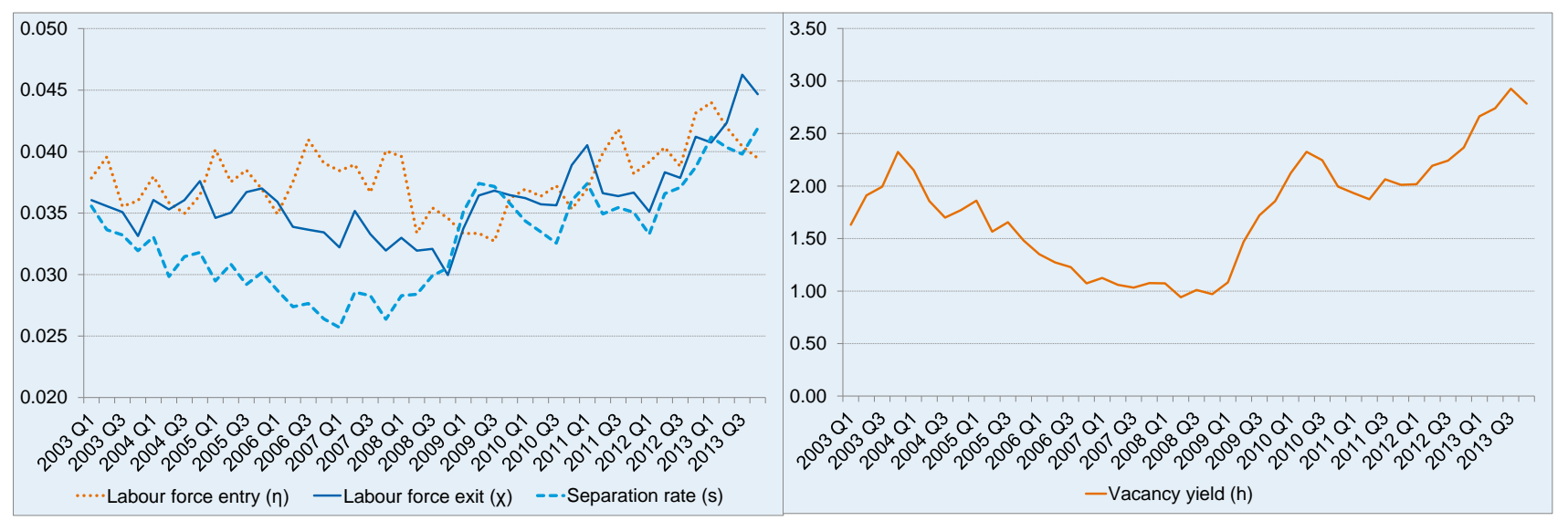

Source: Statistics Netherlands.

\section{Sector data}

We are able to gather data for a maximum of 28 sectors covering the period 1999-2014 (Q2) (see Appendix A.4). Although a higher level of disaggregation is always preferable ${ }^{11}$, the sector composition used in our analyses is already broken down to a higher extent than possible based on the available online data on vacancies by Statistics Netherlands. The disaggregated vacancy data was provided by Statistics Netherlands. Figure A.3 in the Appendix A.10 shows that the spread in the $v / u$-ratios of the 28 examined industries is low in recent years.

In contrast to data availability for our macro analysis, we need to overcome several data problems in order to examine mismatch on the sector level. First, we lack survey data on unemployment by sector. Therefore, we use ultimo data on registered unemployment benefits per sector as a proxy. ${ }^{12}$ These administrative data are provided by UWV (the Dutch Employee Insurance Agency). The number of people receiving unemployment benefits is lower than the number of unemployed, because not all unemployed

\footnotetext{
${ }^{9}$ Detrending the flows data, by using, for example, a HP-filter (see, e.g. Barnichon, 2012), would violate our steady-state condition, since we would have to subtract two different values on both sides of the equation, e.g.: $\left(f_{t}-d_{f}(t)\right)-\left(s_{t}-d_{s}(t)\right) \neq f_{t}-s_{t}=0$ if $d_{f}(t) \neq d_{s}(t)$, where $d_{f}(t)$ and $d_{s}(t)$ are the trends from $f_{t}$ and $s_{t}$, respectively. Therefore, we do not detrend the data.

10 The labour force in the labour force survey (LFS) of Statistics Netherlands is defined as the amount of people who work at least twelve hours a week or want to work at least twelve hours a week and have undertaken search efforts to find a job of at least twelve hours a week. Employment is defined as the residents in the Netherlands who have a paid job of at least twelve hours a week. Unemployment is defined as all persons unemployed or working less than 12 hours a week, who are willing and searching for work for at least 12 hours a week. The ILO-definition regarding these variables does not have the 12-hour threshold.

${ }^{11}$ Elsby et al. (forthcoming) emphasize that joining markets (i.e. sub-sectors) lowers the likelihood of mismatch, as some markets (i.e. sub-sectors) with unemployed workers will be joined with vacant jobs.

${ }^{12}$ The unemployment rate is proxied by the number of unemployment benefit recipients at the beginning of the year as a ratio of the number benefit recipients plus the number of working employees.
} 
have access to unemployment benefits (e.g. new graduates or labour market re-entrants). ${ }^{13}$ However, data on the number of unemployment benefits is highly correlated with unemployment, making it a good proxy for the cyclical behaviour of unemployment. The correlation coefficient over the period 2003-2013 is 0.97. The major drawback in using unemployment benefit recipients as a proxy for unemployment is that the age distribution differs between both variables. Especially the young have relatively short employment spells and hence enjoy benefits for a shorter period of time. Moreover, the sector distribution of youth unemployment is probably different from the unemployed that we take into consideration in our analysis; a large part of youth unemployment consists of youngsters looking for a job on the side and these jobs are mainly located in sectors such as hotels and restaurants, retail and cleaning (Bierings and De Vries, 2014). As a consequence, we could underestimate mismatch. However, this underestimation might not be too problematic. The unobserved mismatch related to youth unemployment is most likely transitory in nature. After graduation, most unemployed young job seekers will start looking for a job in different sectors. In addition, the share of labour market re-entrants in total unemployment in the Netherlands is less than 10 percent.

Second, employment data for our sector composition is only available for a couple of recent years. This complicates the calculation of the separation rate on the sector level, which we need in order to derive our sector steady-state curves. As an alternative we use administrative data on the number of people who have disability and unemployment insurance (excluding the actual recipients of benefits), covering the period 1999-2013. Arguably, the number of insured is a better indicator than the amount of persons employed or the number of employees, since the number of insured also covers self-employed with secondary jobs, who also have access to unemployment benefit schemes. ${ }^{14}$

Third, since a large share of the people who receive unemployment benefits exit the programme without finding a job, we have to rely on exits rates from unemployment benefit schemes rather than job-finding rates. Using job-finding rates would imply a steady-state rate of unemployment which deviates substantially from the actual unemployment rate. That means that using job-finding rates would give a poor approximation of unemployment dynamics and hence the counterfactual unemployment level that we calculate with these rates would be a poor approximation as well. Therefore, the exit rate is used as a proxy of the job-finding rate and is defined as the sum of people exiting unemployment benefits (either because they find work or because of benefits exhaustion) as a fraction of the number of unemployment benefit recipients. Consequently, we equate the inflow into unemployment benefits to the outflow of unemployment benefits and consider this as our steady-state situation.

In addition, exit rates might differ between sectors, not only because of differences in matching efficiency, but also due to differences in the length of benefit durations. In the Netherlands, benefit durations depend on the length of employment history and this likely differs between sectors. Workers in the hotels and restaurants, for instance, have short employment spells due to seasonal fluctuations and have, on average, shorter benefit durations. As a consequence, our social planner will move unemployed to sectors where short-term contracts are common, since the exit rate in these sectors is high. This is problematic if the hiring rate in those sectors is low. In that case, our assumption of an omniscient social planner is violated and the planner will move too many unemployed to these sectors, which is not optimal. However, the hiring and exit rates in all individual sectors are strongly positively correlated, indicating that the use of exit rates does not misinform our social planner.

\section{Results}

\subsection{Macro results}

In order to derive a steady-state Beveridge curve at the aggregate level, we estimate equation (7) in Section 2.1. Table 1 shows the estimation results of our total sample. We also conduct estimates for two other sample periods: a sample covering the pre-crisis observations (2003Q1-2008Q3) and a crisis

\footnotetext{
${ }^{13}$ In our data on unemployment benefit recipients we have excluded people that took part in the so-called "deeltijd-WW". The deeltijd-WW was a temporary short-time working scheme between April 2009 and July 2011. The aim of the scheme was the prevention of layoffs during the Great Recession, by providing employers with a wage cost subsidy if they reduced the working hours of their employees. People participating in short-time working schemes still have work and are often not actively searching for a job. Therefore, we find it more accurate to exclude this specific group from our proxy for unemployment.

${ }^{14}$ Due to limited data availability, we have used the mutation of the number of employed persons at the sectoral level as a proxy for the mutation of the number of insured in 2014 relative to 2013.
} 
sample (2008Q4-2013Q4). ${ }^{15}$ The estimation results are reported in Appendix A.5: Table A.1. To resume, the alphas in Table 1 show the relationship between four different labour market flows (the separation rate, the hire rate, labour force outflow, and labour force inflow) on the one hand and labour market tightness measured by the $v_{t} / u_{t}$-ratio on the other hand.

The negative effect $(-0.182)$ of labour market tightness on the separation rate is straightforward: when labour market tightness increases (i.e. $v_{t} / u_{t}$ increases), the number of layoffs decline, as work is abundant and employers have more difficulty finding appropriate employees. The estimated coefficient of our separation rate is close to the results of Barnichon et al. (2012): they find an effect of labour market tightness (measured by the $v / u$-ratio) on the layoffs rate in the US of -0.11 .

With respect to the hire rate $\left(h_{t}\right)$, the negative relationship $(-0.623)$ is also as expected. As labour market tightness increases, it becomes more difficult for employers to fill their job openings and hence the number of hires per vacancy (i.e. the hire rate) drops. In all three samples, changes in the $v_{t} / u_{t}$-ratio explain more than $90 \%$ of the fluctuation in the hire rate. Again, our results resemble those of Barnichon et al. (2012), although their estimated coefficient is somewhat higher (-0.41).

Table 1. Estimation results of three-state labour market model, macro level

\begin{tabular}{|lcccc}
\hline & & & \\
& Separation rate & Hire rate & Labour force exit & Labour force entry \\
\hline & $\ln \left(s_{t}\right)$ & $\ln \left(\boldsymbol{h}_{t}\right)$ & $\ln \left(\boldsymbol{\chi}_{t}\right)$ & $\ln \left(\eta_{t}\right)$ \\
\hline Constant $(\beta)$ & $-3.62^{* * *}$ & $-0.15^{* * *}$ & $-3.48^{* * *}$ & $-3.33^{* * *}$ \\
\hline $\ln \left(v_{t} / u_{t}\right)(\alpha)$ & $-0.182^{* * *}$ & $-0.623^{* * *}$ & $-0.145^{* * *}$ & -0.050 \\
\hline $\mathrm{R}^{2}$ & 0.48 & 0.92 & 0.67 & 0.13 \\
\hline S.E. & 0.09 & 0.09 & 0.05 & 0.07 \\
\hline N (observations) & 44 & 44 & 44 & 44
\end{tabular}

HAC standard errors and covariance. Significant at * $10 \% ; * * 5 \% ; * * * 1 \%$.

In addition, the estimates show a significant relationship $(-0.145)$ between labour market tightness and exits from the labour market. This effect can be interpreted as the "discouraged worker effect" (e.g. Clark and Summers, 1981; Cahuc and Zylberberg; 2004; Deloach and Kurt, 2012). When labour market prospects deteriorate (i.e. the number of vacancies declines and unemployment rises), job finding opportunities become slim and search costs are increasing, which consequently discourages people to actively search for work. These search costs involve both monetary and psychological costs. This results differs from the results of Barnichon et al. (2012), who do not find any meaningful explanatory power of labour market tightness on either labour force entry or exits.

Based on the pre-crisis sample and total sample estimates, we do not find a significant impact of labour market tightness on labour force entry $\eta_{t}$. From a theoretical perspective, one might expect a negative relationship, indicated in the literature as the "added worker effect": households that are faced with negative shocks in wealth and income due to worsening labour market perspectives (i.e. decreasing labour market tightness) can increase labour supply to smooth life-time consumption (e.g. Lundberg, 1984; Spletzer, 1997). The added worker effect relates to people that are currently inactive on the labour market, e.g. the retired, students or labour market re-entrants. Our estimates only register a continuous entry rate (indicated by the significant constant term in Table 1: -3.33). However, estimates based solely on crisis observations do show a significant negative relationship between labour market tightness and labour force entry (see Table A.1). Perhaps, the added worker effect was more important during the Great Recession compared with the previous less severe downturn. Evidence by Van den Berghe et al. (2014) shows that during the second phase of the Great Recession, the number of people who entered the Dutch labour market increased substantially, which could be related to increasing losses in housing wealth, rising unemployment (probabilities), or a high overall level of uncertainty. This stimulated people who were not previously active on the labour market to search for a job.

\footnotetext{
${ }^{15}$ The start of the Great Recession is identified based on data regarding quarterly GDP volume mutations. Although the third quarter already shows a slight decline of $0.1 \%$, the crisis intensified significantly in the fourth quarter of $2008(-1.0 \%)$.
} 
We use the coefficients estimated in Table 1 to solve our steady-state Beveridge curve, as the implicit solution shown in equation (8). Figure 3 shows the steady-state Beveridge curve for the total sample period. We have also plotted a $90 \%$ confidence band based on a bootstrapping procedure. ${ }^{16}$ This band shows that our steady-state curve can be estimated with reasonable precision. We can draw several conclusions from Figure 3. The steady-state Beveridge curve has the expected convex shape and a large part of the observations differ significantly from the steady state: the well-known cyclical behaviour. We can clearly see that the vacancy-unemployment relationship shows the expected anti-clockwise cyclical pattern around the steady-state curve. The last three crisis observations (2013Q2-Q4) are located close to the steady-state curve.

Figure 3. Steady-state Beveridge curve for the Netherlands

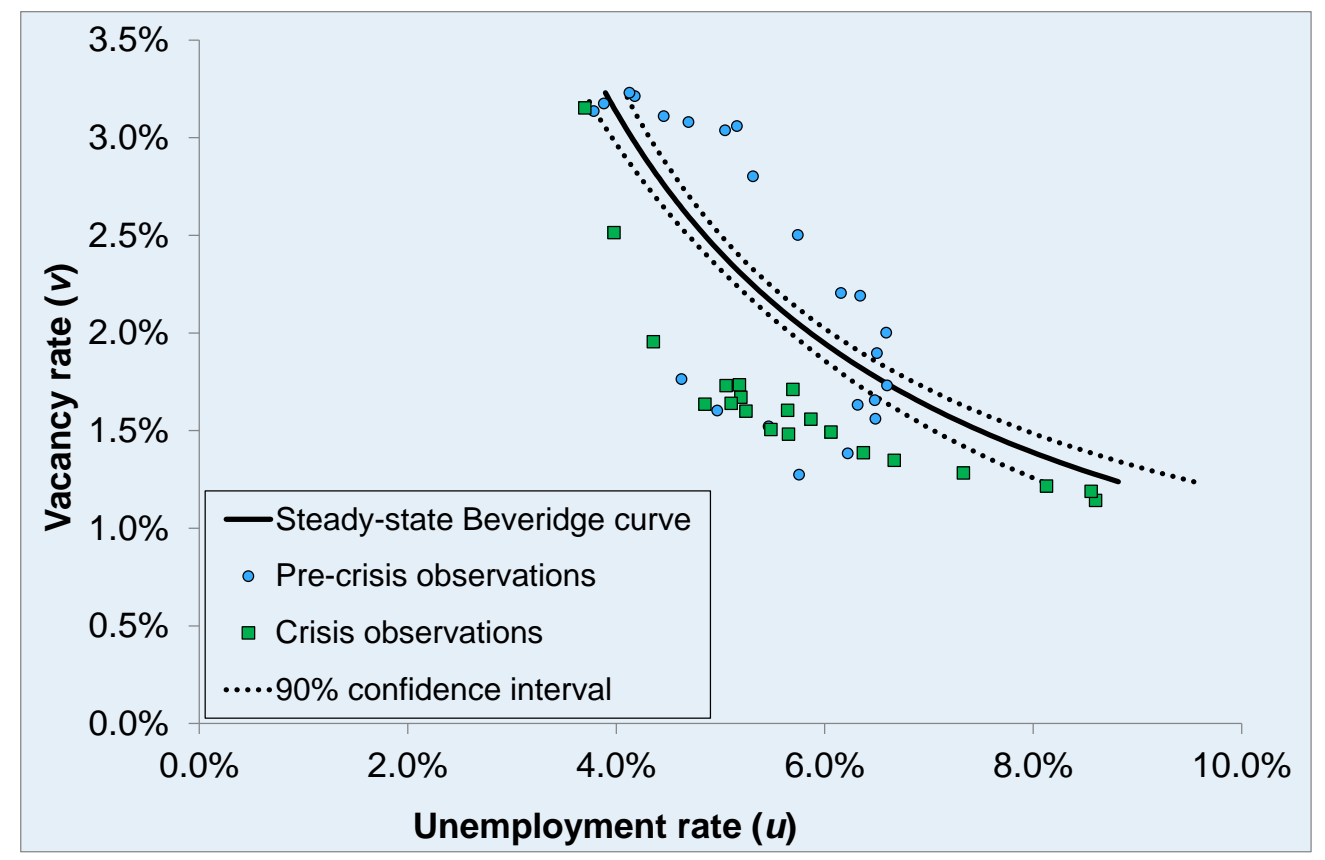

Source: own calculations based on data from Statistics Netherlands.

Next, we formally test for an outward shift of the curve by testing for a structural break between the precrisis and crisis steady-state Beveridge curve. Both Beveridge curves are derived as the solution of the steady-state equations. These functions can be described by a power function. In order to study if a structural break is apparent, we bootstrap the estimation process based on a pre-crisis and crisis sample and test for a significant break in the two estimated parameters of the power functions. We find that there is no significant structural break, when testing the significance of the individual parameters and the joint significance. We have included the pre-crisis and crisis steady-state Beveridge curve and the corresponding confidence intervals in Appendix A.6 along with an extensive discussion of the testing methodology.

\section{Expected Beveridge curve development post-crisis}

An important question is how movements along the steady-state Beveridge curve will unfold in the years to come. This question is important, since 2014 can be seen as the turning point of the business cycle and the start of the recovery phase in the Netherlands. We do not have sufficient data, however, to estimate a steady-curve Beveridge curve during the recovery phase. Therefore, we have to rely on the 2014 observations and compare these with an expected recovery path. Blanchard and Diamond (1989) argue that temporary deviations from the Beveridge curve can be quite strong during the adjustment period. Hence, we need to take the cyclical deviations from the Beveridge curve into consideration when constructing our recovery path. We assume that temporary deviations during the current recovery phase follow a similar pattern vis-à-vis the pre-crisis period, but the scale is different depending on the severity of the crisis. This assumption allows us to estimate the recovery path using observations from the

\footnotetext{
${ }^{16}$ Bootstrapping means that we draw one thousand samples from our quarterly observations with replacement. Using these samples, we have again performed the regressions and derived steady-state Beveridge curves. Using all those generated Beveridge curves, we can determine the $90 \%$ confidence interval.
} 
previous recovery phase. For details on the technical aspects of the model for our recovery path, see Appendix A.7.

The recovery path is illustrated in Figure 4 by the orange curve. This curve should be interpreted as a bandwidth based on experiences from the previous cycle. Observations within this bandwidth reflect cyclical fluctuations, whereas observations beyond our recovery path might point towards structural problems, reflected by a lower matching efficiency.

Now, in order to test how the labour market is moving along our expected path of recovery, we plot the observations of the vacancy and unemployment rate combinations for the post-crisis period, indicated by the five yellow dots. Most of the five observations are below our predicted recovery path. Deviations from the steady-state Beveridge curve during the current recovery are not very different from deviations observed in the previous periods of recovery. Hence, from a macro perspective, there are no indications that the Beveridge curve has shifted outwards and mismatch is a big problem on the Dutch labour market. ${ }^{17}$

\section{Figure 4. Expected recovery path along the Beveridge curve}

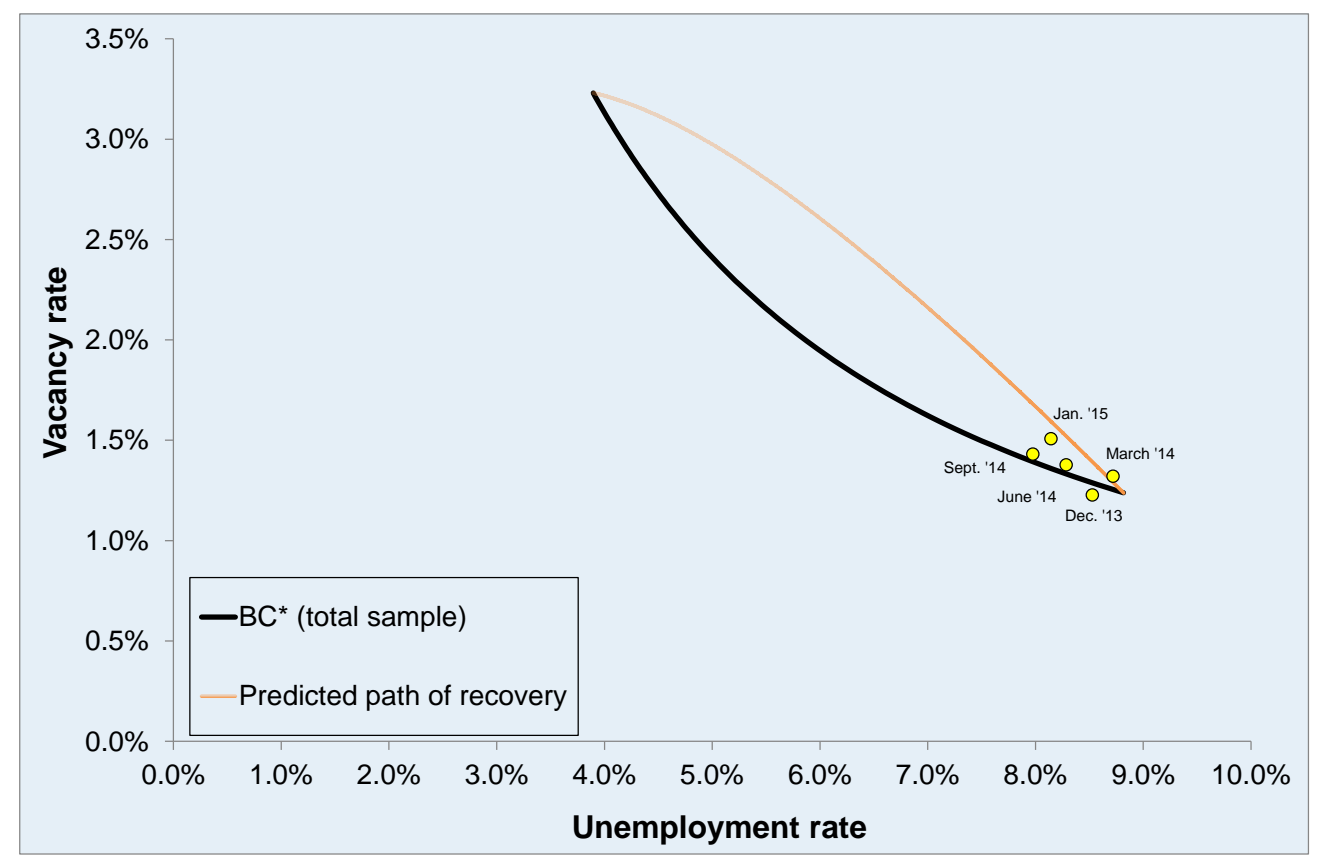

Source: own calculations based on data from Statistics Netherlands.

\subsection{Sector mismatch}

As explained above, an aggregate perspective might miss heterogeneity at the sector level. Therefore, we also need to examine Beveridge curves shifts at a lower level of aggregation, i.e. the sector level. Appendix A.8 deals with mismatch within sectors, or intrasectoral mismatch. This section will focus on mismatch between sectors (i.e. sector mismatch) using the mismatch index developed by Şahin et al. (2014) (see Section 2.2). Recall that this mismatch index examines the spread in sectoral $v_{t} / u_{t}$-ratios and differences in matching efficiencies. A high spread indicates a high degree of sector mismatch, as some sectors cope with tight labour markets and labour supply shortages (i.e. high $v_{t} / u_{t}$-ratios), whereas other sectors are dealing with abundant personnel and unemployment (i.e. low $v_{t} / u_{t}$-ratios).

To estimate our mismatch index illustrated in equation (15), we first need to obtain regression parameters by estimating equation (16). Given the data limitations reported in Section 3, keep in mind that we use the number of exits from unemployment schemes as a proxy for the number of hires $H$ and the

\footnotetext{
${ }^{17}$ In the Netherlands the number of discouraged workers has increased in 2014. This discouragement could be the result of increasing mismatch on the labour market, so this is something we have to take into account when analysing macro mismatch. Therefore, we have performed an additional analysis, where we add all the discouraged workers in 2014 to our pool of unemployed. Although the 2014 observations do show a small shift to the right, they remain very close to the derived Beveridge curve and our calculated recovery path. Thus, including the increasing amount of discouraged workers in 2014 in our analysis does not alter our conclusion that mismatch on the macro level is relatively low in the Netherlands.
} 
number of unemployment benefits recipients as a proxy for the number of unemployed $U$. The regression results are reported in Table A.3 in Appendix A.9.18

Next, we use the parameters from Table A. 3 to derive our mismatch index. Figure 5 shows the development of both the homogeneous and heterogeneous mismatch index for the Netherlands. As discussed, the mismatch index measures the fraction of the amount of hires that is lost due to inefficient allocation. Therefore, a decline of the mismatch index does not necessarily imply that the number of hires lost has also decreased. The homogeneous index only takes differences in labour market tightness into account, while the heterogeneous index looks at differences in matching efficiency as well. In order to obtain confidence intervals for our mismatch indices, we performed a block-bootstrap (to maintain correlation within sectors). This means that we drew a sample of 28 sectors from our data one thousand times (with replacement) and subsequently calculated the corresponding mismatch indices. The result of this procedure is illustrated in Figure 5 by the dashed confidence intervals.

\section{Figure 5. Sector mismatch index}

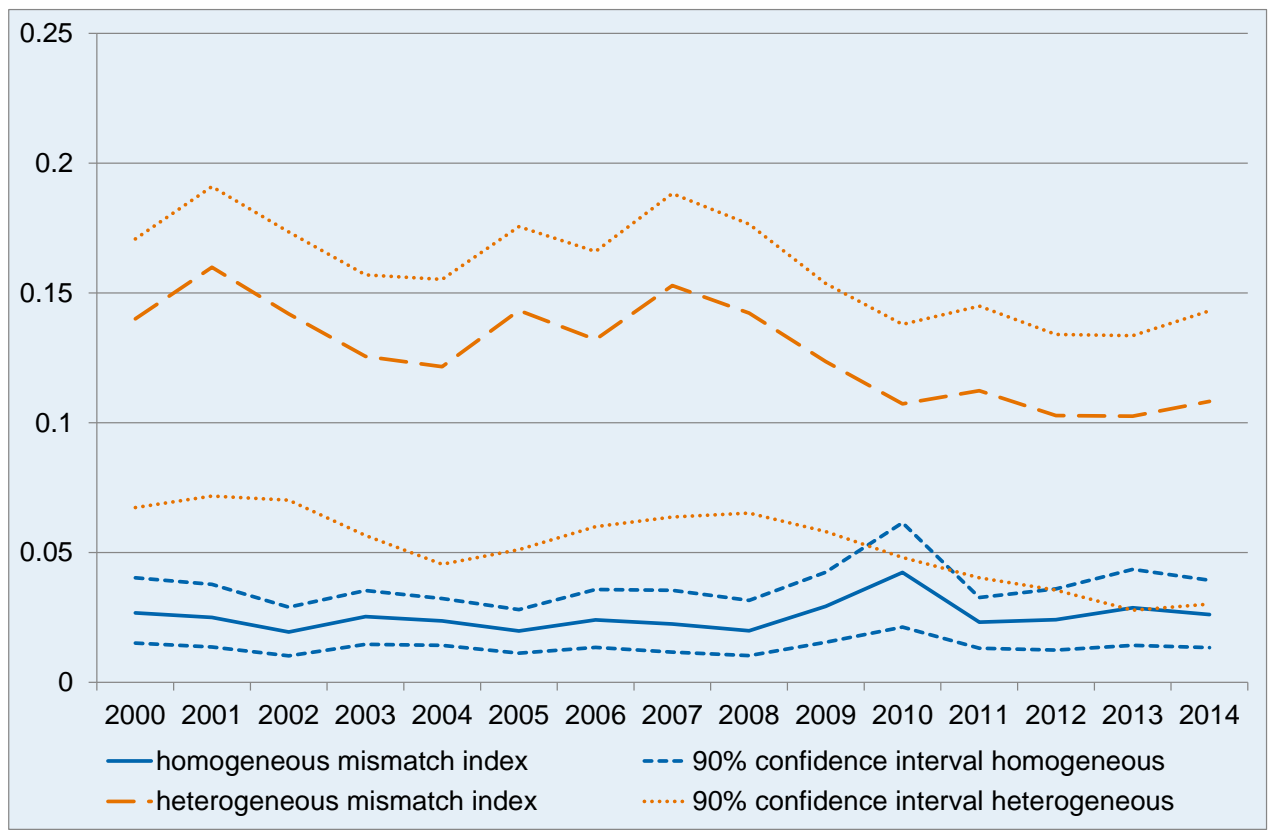

Source: own calculations based on data from Statistics Netherlands and UWV. The dashed lines represent the $95 \%$ confidence bounds.

The level of the homogeneous index lies below the heterogeneous one substantially $(2.5 \%$ versus $12.7 \%$ on average), which reflects differences in matching efficiency across sectors. The development of our homogenous index is equal to the index calculated for the Netherlands by Arpaia et al. (2014), although their level is somewhat higher. Differences also exist in the development during the Great Recession: the homogeneous index displays a sharp peak in 2009-2010, which is due to the fact that some sectors (e.g. manufacturing and transport) experienced the adverse shock much quicker than others (e.g. public sector and health care). This created a large but temporary increase in the vacancy shares of the public sector and the health care sector (See Appendix A.10), which resulted in a transitory increase in differences in labour market tightness between sectors. The heterogeneous index shows a decline during the Great Recession, with a slight increase in $2014 .{ }^{19}$ The decline can be explained by a decrease of vacancy shares of sectors with above-average matching efficiency (e.g. construction, agriculture, retail and employment agencies). This limits the social planner's capability to move the unemployed to sectors with a high matching efficiency. Hence, the counterfactual amount of hires is closer to the actual amount.

Both indices reveal that mismatch between sectors does not seem to have increased during the Great Recession. The levels we find for the heterogeneous mismatch index are about three times higher than the

\footnotetext{
18 We have tested the assumption of constant returns to scale in our matching function for all 28 sectors using the Wald test. Two sectors display increasing returns to scale and seven show decreasing returns to scale. Since the planner assumes constant returns to scale, the planner's allocation might not be optimal and mismatch could be over or underestimated. As a robustness check, therefore, we ran our analyses leaving out the nine sectors from our sample that do not meet the constant returns to scale constraint. The results only differ marginally from our estimation using the complete sample.

${ }^{19}$ The decrease in the heterogeneous mismatch index between 2007 and 2010 is statistically significant (at 5\%). Results are available on request.
} 
levels reported by Şahin et al. (2014) for the United States for a comparable period. This difference can be explained by the higher estimate of the vacancy share ( $\alpha$ in the matching function) found by Şahin et al. (2014); 0.5 in the United States against 0.17 for the Netherlands. Our lower estimate of the vacancy share can be explained by our use of administrative data instead of survey data. We thereby miss successful matches between unemployment and vacancies, leading to a lower estimate of the vacancy yield. Şahin et al. (2014) use survey data. When we use a vacancy share of 0.5 , the level of our heterogeneous index is comparable with the one of Şahin et al. (2014). ${ }^{20}$ Furthermore, the United States has a more flexible labour market and a stricter social benefits regime, which could also explain our lower vacancy share. Both factors contribute to a more efficient allocation of the unemployed across sectors. Less generous unemployment benefits induce the unemployed to also look for jobs outside their sector and a flexible labour market helps to facilitate those transitions.

\section{Contribution of sector mismatch to unemployment}

Next, we calculate unemployment in a world without mismatch, by using the optimal hires set by the social planner (equation 18). Figure 6 shows this counterfactual level of unemployment, as well as actual unemployment. We use the actual unemployment level in 1999 as the starting point for our counterfactual unemployment level. This initial unemployment condition is not important, as it only marginally affects the development of the counterfactual unemployment level up till 2004.21

\section{Figure 6. Unemployment and the planner's counterfactual unemployment}

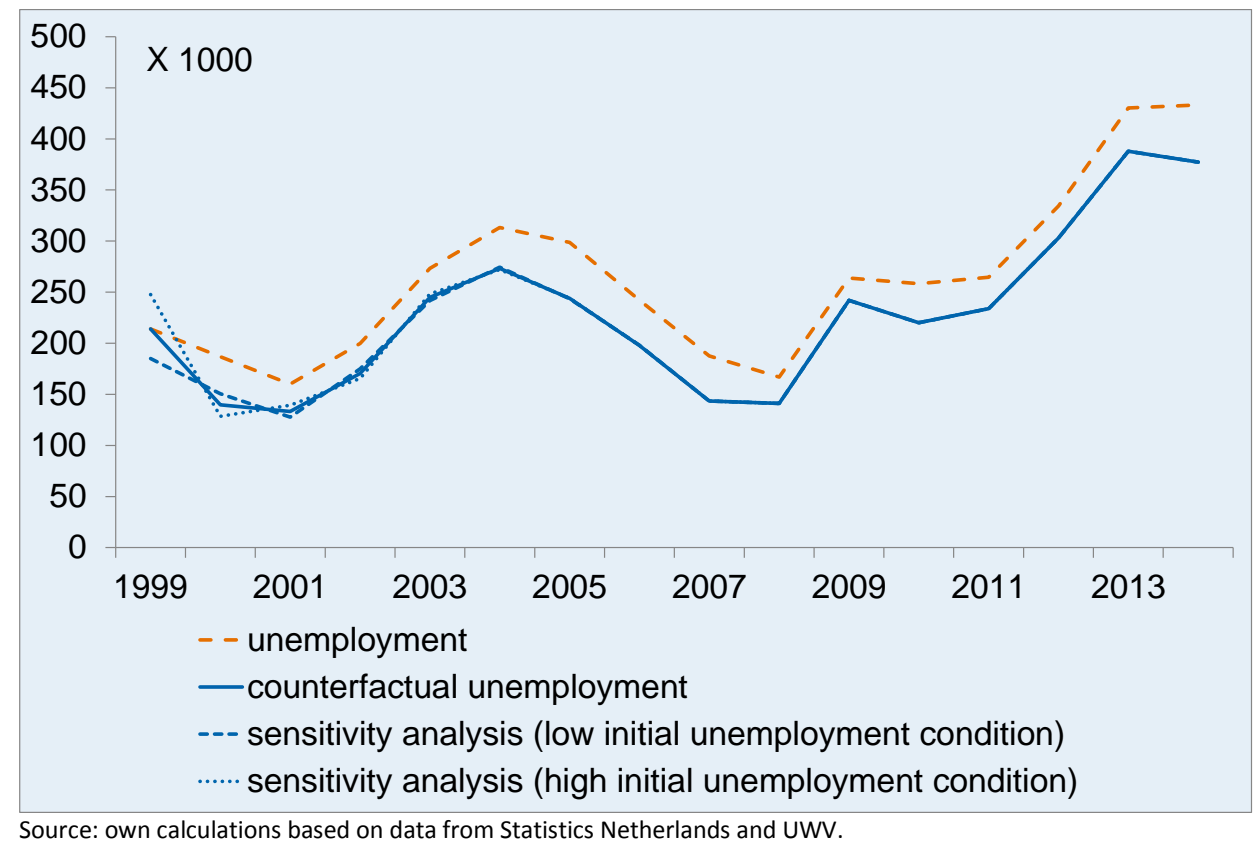

Table 2 reports the gap between actual unemployment and counterfactual unemployment (i.e. unemployment that can be attributed to mismatch). The right column shows that mismatch unemployment has dropped during the Great Recession, from 24\% in 2007 to 13\% in 2014. The recent amount of mismatch (10\% in 2013 and 13\% in 2014) is lower than in earlier years. From an international perspective, the contribution of mismatch to the current unemployment rate also seems to be well below other countries that were examined with respect to sector mismatch. Şahin et al. (2014) find that mismatch across industries explains up to one-third of the total observed increase of the unemployment rate in the United States. A similar estimate is found by Marthin (2013) for Sweden. Shibata (2013) shows that occupational mismatch (which is closely related to sector mismatch) explains roughly 10 to $30 \%$ of the unemployment increase in Japan during the Great Recession.

\footnotetext{
${ }^{20}$ Setting the vacancy share $(\alpha)$ at a value of 0.5 instead of 0.17 , lowers the contribution of mismatch to Dutch unemployment. This can be explained by the fact that a higher vacancy share lowers the impact of sector matching efficiencies when constructing the mismatch index. Hence, our estimate of the contribution of mismatch to Dutch unemployment must be considered as an upper bound.

${ }^{21}$ In order to assess the influence of our initial unemployment condition, we have also estimated counterfactual unemployment using a lower and higher initial unemployment condition (the dashed and dotted blue lines in Figure 6). For the lower unemployment condition we use $85 \%$ of the real unemployment rate. For the higher unemployment scenario we used a $15 \%$ higher unemployment condition. It is clear that the impact of the initial condition peters out when moving forward in time; the influence is negligible after 2004
} 
Table 2 also shows that mismatch unemployment seems to be pro-cyclical: it rises during periods of economic expansion, and decreases during downturns. In addition, mismatch unemployment reaches its peak in years preceding a recession, i.e. in 2000 before the dotcom-crisis (25\%) and in 2007 before the Great Recession (24\%). This is related to the cyclical behaviour of the heterogeneous mismatch index: during upswings the vacancy shares of sectors with above-average matching efficiency increase, which leaves the social planner with more room to increase the amount of hires.

The cyclical behaviour is also caused by composition effects of the pool of unemployed. In a tight labour market prior to a recession (high demand for labour in specific industries), people who are dealing with unemployment spells will generally have less favourable worker skills and hence are relatively more difficult to match. ${ }^{22}$

Table 2. Difference between actual and counterfactual unemployment

\begin{tabular}{|lcc|}
\multicolumn{2}{|c|}{$\begin{array}{c}\text { Difference between } \boldsymbol{U}_{\boldsymbol{t}} \\
\text { and } \boldsymbol{U}_{\boldsymbol{t}}^{*}(\mathbf{X} \mathbf{1 . 0 0 0})\end{array}$} & $\begin{array}{c}\text { Difference as percentage of total } \\
\text { unemployment } \boldsymbol{U}_{\boldsymbol{t}}\end{array}$ \\
\hline $\mathbf{2 0 0 0}$ & 47 & 25 \\
\hline $\mathbf{2 0 0 1}$ & 27 & 17 \\
\hline $\mathbf{2 0 0 2}$ & 29 & 15 \\
\hline $\mathbf{2 0 0 3}$ & 28 & 10 \\
\hline $\mathbf{2 0 0 4}$ & 40 & 13 \\
\hline $\mathbf{2 0 0 5}$ & 55 & 18 \\
\hline $\mathbf{2 0 0 6}$ & 44 & 18 \\
\hline $\mathbf{2 0 0 7}$ & 44 & 24 \\
\hline $\mathbf{2 0 0 8}$ & 26 & 15 \\
\hline $\mathbf{2 0 0 9}$ & 22 & 8 \\
\hline $\mathbf{2 0 1 0}$ & 38 & 15 \\
\hline $\mathbf{2 0 1 1}$ & 31 & 12 \\
\hline $\mathbf{2 0 1 2}$ & 31 & 9 \\
\hline $\mathbf{2 0 1 3}$ & 42 & 10 \\
\hline $\mathbf{2 0 1 4}$ & 56 & 13 \\
\hline
\end{tabular}

Source: own calculations based on data from Statistics Netherlands and UWV.

It is important to stress that the amount of mismatch reported in this section - measured as the gap between actual and counterfactual unemployment - should be considered as an upper bound, because we abstract from moving costs between sectors, such as retraining costs. Therefore, not all transitions that the planner suggests are feasible or worth the costs. In this light, mismatch on the Dutch labour market seems to be even less of a problem than already suggested by the mismatch index.

A drawback of our analysis is that we do not calculate counterfactual unemployment rates for occupational and geographical mismatch, thereby missing potential sources of mismatch in our analysis. However, we are able to calculate mismatch indices for these two types of mismatch. These indices only take differences in labour market tightness into account and abstract from differences in matching efficiency (Jackman and Roper, 1987). This type of index measures the distances of occupational or regional $v_{i t} / u_{i t}$-ratios from the aggregate $v_{t} / u_{t}$-ratio. ${ }^{23}$ We use administrative data on vacancies and registered job seekers for 128 different occupations and 38 regions covering the years 2011-2014. Figure 7 shows that both indices are at a low level, since the index can only take values between 0 and $1 .{ }^{24}$ Our estimate of occupational mismatch is comparable to what Shibata (2013) finds for Japan, but it is much lower than what Lazear and Spletzer (2012) find for the US. ${ }^{25}$ Unfortunately, we cannot compare our

\footnotetext{
${ }^{22}$ The rise of mismatch in 2010 is probably due to these composition effects. In general, people who became unemployed at the beginning of the crisis (2008-2009) will be the first ones to find work when the economy picks up again, such as the short-lived recovery in 2010. The people who were already difficult to match before the crisis will have a higher chance of remaining unemployed.

${ }^{23}$ Following Lazear and Spletzer (2012), we calculate the distance measure as $M_{t}=\frac{1}{2} \sum_{i}\left|\frac{u_{i t}}{u_{t}}-\frac{v_{i t}}{v_{t}}\right|$.

${ }^{24}$ If there is no mismatch, the aggregate $v_{t} / u_{t}$-ratio equals the occupational or regional $v_{i t} / u_{i t}$-ratio: $\frac{v_{t}}{U_{t}}=\frac{v_{i t}}{U_{i t}}$ which can be rewritten as $\frac{U_{i t}}{U_{t}}-\frac{v_{i}}{v_{t}}=0$. Substituting this into our distance measure equation $M_{t}$ gives 0 . If there is complete misalignment, one half of the regions has zero unemployment and a positive amount of vacancies. The other half has zero vacancies and positive unemployment: $M_{t}=\frac{1}{2} \sum_{i}\left|\frac{u_{i}}{u_{t}}-\frac{0}{v_{t}}\right|+\frac{1}{2} \sum_{i}\left|\frac{0}{u_{t}}-\frac{v_{i t}}{v_{t}}\right|=1$.

${ }^{25}$ Since both Lazear and Spletzer (2012) and Shibata (2013) look at a lower amount of sectors than our study, we have to block bootstrap our simple mismatch index to compare our findings to theirs. Our block bootstrapped estimate is 0.24 when we look at the same number of sectors used by Shibata (2013) and this is close to his estimate of 0.23 . However, we find a much lower level of occupational mismatch (0.12) than Lazear and Spletzer, who find a level of about 0.4 .
} 
degree of regional mismatch to other studies, because of differences in the type of mismatch indices used. Moreover, occupational and regional mismatch do not seem to have increased during the last years of the Great Recession. Due to data limitations, however, we do not know whether regional and occupational mismatch have increased vis-à-vis their level prior to the Great Recession. Further research should shed more light on this issue.

\section{Figure 7. Occupational (left) and regional (right) mismatch index}

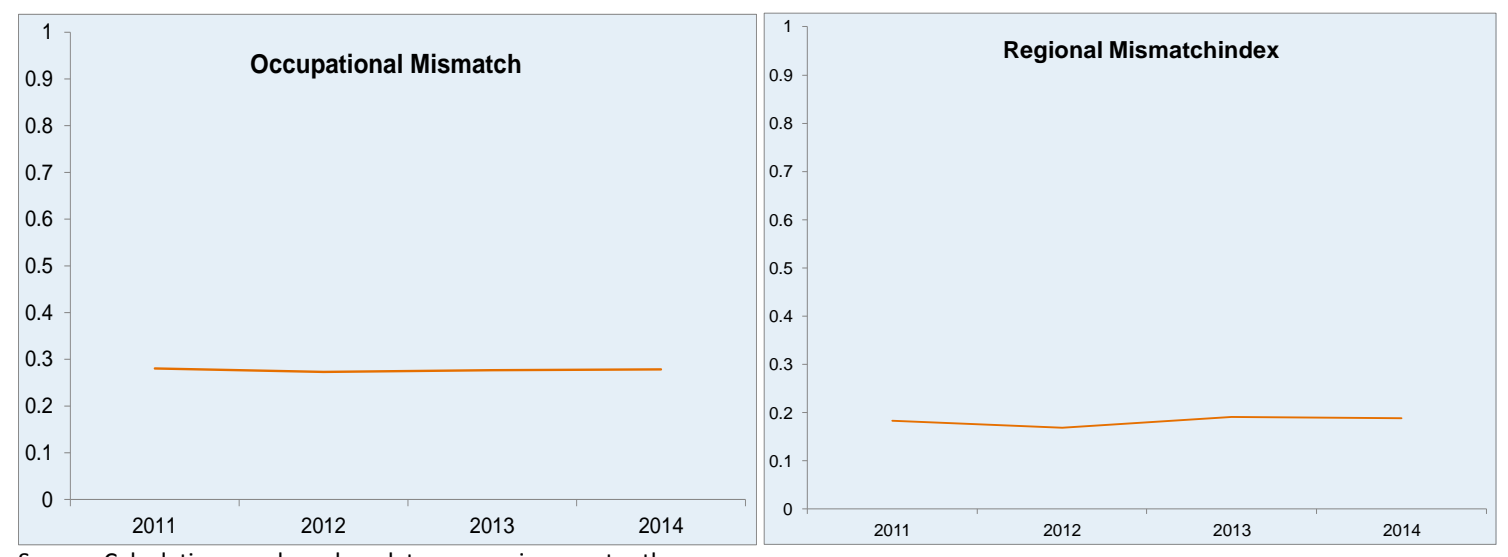

Source: Calculations are based on data concerning quarter three.

\section{Conclusion}

In this article, we have examined mismatch on the Dutch labour market from an aggregate and sector perspective. We have analysed mismatch on the aggregate level by deriving a steady-state Beveridge curve, which is based on the integration of four labour market equations that describe the matching process on the labour market. To measure mismatch, we constructed an expected recovery path along the Beveridge curve, which takes average deviations from the steady-state curve into account. Our post-crisis observations lie close to or underneath this recovery path, suggesting that there has not been a significant increase in mismatch on the Dutch labour market as a result of the Great Recession.

As the macro perspective might miss heterogeneity on a lower level of aggregation, we also examine sector mismatch using a mismatch index. Our estimates show that less than one-seventh of the rise of unemployment during the Great Recession can be attributed to sector mismatch. This means that by better allocating the unemployed across sectors, unemployment can lowered by at most $13 \%$. This percentage has to be regarded as an upper bound, since we abstract from moving costs between sectors (e.g. schooling and (re)training). Some sector transitions will therefore be not feasible or worth the costs. Furthermore, our analysis shows that the amount of sector mismatch has fallen since the crisis and its level is low from an international and historical perspective. Lastly, a first glance of occupational and geographical mismatch - using a simple mismatch index - does not show any increase in these types of mismatch during the Great Recession.

Finally, we want to touch on some policy implications. The current labour market policy in order to fight the high unemployment in the Netherlands largely focuses on fostering labour market mobility and schooling. This policy hinges on the assumption that jobs are readily available in some parts of the Dutch economy, whereas other sectors are coping with high numbers of unemployment. In this article, we have shown that the economic shock caused by the Great Recession seems to have hit all Dutch sectors simultaneously, raising questions about the effectiveness of stimulating labour market transactions and schooling on a large scale. Of course, initiatives to foster labour mobility can be considered no-regret policies in order to smooth labour market matches that are possible. Moreover, certain sectors that have difficulties recruiting qualified personnel, such as the IT sector, will benefit from the initiated policies. However, our results show that the contribution of sector mismatch to the current level of unemployment is at most $13 \%$. Given this outcome, it is recommended to focus on the forces causing the remaining $87 \%$ of the current unemployment level. Determining these forces is beyond the scope of this paper, but given the large output gap, weak aggregate demand is a plausible candidate. 


\section{Literature}

Aaronson, D. and J. Davis (2011), How much has house lock affected labor mobility and the unemployment rate?, Chicago Fed Letter.

Arpaia, A., A. Kiss and A. Turrini (2014), Is unemployment structural or cyclical? Main features of job matching in the EU after the crisis, Economic Papers 527, European Commission, Brussels.

Ball, L.M. (2009), Hysteresis unemployment: Old and new evidence, National Bureau of Economic Research, NBER Working Paper, no. 14818, Cambridge (Mass.).

Barnichon, R., (2012), Vacancy posting, job separation and unemployment fluctuations, Journal of Economic Dynamics and Control, 36(3), pp. 315-330.

Barnichon, R., M. Elsby, Hobijn, B. and A. Şahin (2012), Which industries are shifting the Beveridge curve?, Monthly Labor Review, 135, pp. 25-37.

Barnichon, R. and A. Figura (2011), What drives matching efficiency?: A Tale of composition and dispersion, Division of Research \& Statistics and Monetary Affairs, Federal Reserve Board.

Bauer, T.K. and S. Bender (2004), Technological change, organizational change, and job turnover, Labour Economics, 11(3), pp. 265-291.

Bentolila, S., P. Cahuc, J.J. Dolado, and T. le Barbanchon (2012), Two-tier labour markets in the Great Recession: France versus Spain, The Economic Journal, 122(562), F155-F187.

Bentolila, S., J.J. Dolado and J.F. Jimeno (2012), Reforming an insider-outsider labor market: The Spanish experience, IZA Journal of European Labor Studies, 1(1), pp. 1-29.

Berge, W. van den, H. Erken, M. de Graaf-Zijl and E. van Loon (2014), The Dutch labour market during the Great Recession, CPB background document, The Hague.

Bierings, H. and R. de Vries (2014), Jeugdwerkloosheid als optelsom van twee groepen, Economisch Statistische Berichten, 99(4687), pp. 367-368.

Blanchard, 0. and P. Diamond (1989), The Beveridge curve, Brookings Papers on Economic Activity, 1, pp. 1-76.

Bonthuis, B., V. Jarvis and J. Vanhala (2012), What's going on behind the Euro Area Beveridge Curve?, Mimeo, ECB.

Bouvet, F. (2012), The Beveridge Curve in Europe: New evidence using national and regional data, Applied Economics, 44(27), pp. 3585-3604.

Broersma, L. and J.C. van Ours (1999), Job searchers, job matches and the elasticity of matching, Labour Economics, 6, pp. 77-93.

Caballero, R.J. and M.L. Hammour (1994), On the timing and efficiency of creative destruction, NBER Working Paper, no. 4768, Cambridge (Mass).

Cahuc, P. and A. Zylberberg (2004), Labor Economics, MIT Press, Cambridge (Mass.).

Canon, M.E., M. Chen and A.E. Marifian (2013), Labor mismatch in the Great Recession: A review of indexes using recent US data, Federal Reserve Bank of St. Louis Review, 95(3), pp. 237-272.

Clark, K. and L. Summers (1981), Demographic differences in cyclical employment variation, Journal of Human Resources, 16, pp. 61-79.

CPB (2014), Roads to Recovery, The Hague.

Daly, M.C., B. Hobijn, A. Şahin and R.G. Valletta (2012), A search and matching approach to labor markets: Did the natural rate of unemployment rise?, The Journal of Economic Perspectives, 26(3), pp. 3-26.

Davis, S.J., J. Faberman and J. Haltiwanger (2010), The establishment-level behavior of vacancies and hiring, National Bureau of Economic Research, NBER Working Paper, no. 16265, Cambridge (Mass.).

Davis, S.J. and J. Haltiwanger (1990), Gross job creation and destruction: Microeconomic evidence and macroeconomic implications, in: NBER Macroeconomics Annual 1990, 5, MIT Press, pp. 123-186.

Deelen, A., M. de Graaf-Zijl and W. van den Berge (2014), Labour market effects of job displacement for prime-age and older workers, CPB Discussion Paper 285, The Hague.

DeLoach, S.B. and M. Kurt (2013), Discouraging workers: Estimating the impacts of macroeconomic shocks on the search intensity of the unemployed, Journal of Labor Research, 34(4), pp. 433-454.

Dickens, W.T. and R.K. Triest (2012), Potential effects of the Great Recession on the US labor market, $B E$ Journal of Macroeconomics, $12(8)$.

Donovan, C. and C. Schnure (2011), Locked in the house: Do underwater mortgages reduce labor market mobility?, SSRN 1856073.

Driehuis, W. (1990), A dissteady-state analysis of the Dutch economy, in: J.H. Drèze and C.R. Bean (eds.), Europe's Unemployment Problem, MIT Press, Cambridge Mass, pp. 329-366.

Elsby, M., R. Michaels and D. Ratner (forthcoming), The Beveridge curve: A survey, Journal of Economic Literature. 
Elsby, M., G. Solon and R. Michaels (2009), The ins and outs of cyclical unemployment, American Economic Journal, 1, pp. 84-110.

European Commission (2013), Labour market developments in Europe 2013, European Economy 6|2013, Brussels.

Fujita, S., and G. Ramey (2009), The cyclicality of separation and job-finding rates, International Economic Review, 50(2), pp. 415-430.

Goldin, C. and L. Katz (2008), The Race between Education and Technology, Harvard University Press, Cambridge (Mass.).

Groshen, E.L. and S. Potter (2003), Has structural change contributed to a jobless recovery?, Current Issues in Economics and Finance, 9(8), pp. 1-7.

Hall, R. (2005), Employment fluctuations with steady-state wage stickiness, American Economic Review, 95(1), pp. 50-65.

Hobijn, B. and A. Şahin (2013), Beveridge curve shifts across countries since the Great Recession, IMF Economic Review, 61(4), pp. 566-600.

Jackman, R. and S. Roper (1987), Structural unemployment, Oxford Bulletin of Economics and Statistics, 49(1), pp. 9-36.

Katz, L. (2010), Long-term unemployment in the Great Recession, Testimony for the Joint Economic Committee, US Congress, 29.

Koenders, K. and R. Rogerson (2005), Organizational dynamics over the business cycle: A view on jobless recoveries, Federal Reserve Bank of St. Louis Review, 87(4), pp. 555-579.

Lazear, E.P. and J.R. Spletzer (2012), The United States labor market: Status quo or a new normal?, National Bureau of Economic Research, NBER Working Paper, no. w18386, Cambridge (Mass.).

Loon, E. van, B. Loog, A. van der Horst and M. Souren (2014), De oploop van de werkloosheid ontleed, TPE digitaal, 8(1), pp. 65-83.

Lundberg, S. (1985), The added worker effect, Journal of Labor Economics, pp. 11-37.

Marthin, G. (2012), Measuring mismatch in the Swedish labour market, Swedish Fiscal Policy Council, $2012 / 3$.

Michaels, G., A. Natraj and J. Van Reenen (2014), Has ICT polarized skill demand? Evidence from eleven countries over twenty-five years, Review of Economics and Statistics, 96(1), pp. 60-77.

Modestino, A.S. and J. Dennett (2013), Are American homeowners locked into their houses? The impact of housing market conditions on state-to-state migration, Regional Science and Urban Economics, 43(2), pp. 322-337.

Mortensen, D.T. and C.A. Pissarides (1994), Job creation and job destruction in the theory of unemployment, The Review of Economic Studies, 61(3), pp. 397-415.

Nickell, S., L. Nunziata, W. Ochel and G. Quintini (2003), The Beveridge Curve, unemployment and wages in the OECD from the 1960s to the 1990s, Princeton University Press.

Nickell, S. and J. van Ours (2000), The Netherlands and the United Kingdom: A European unemployment miracle?, Economic Policy, 15(30), pp. 137-180.

OECD (1993), Economic survey of the Netherlands, Paris.

OECD (2012), How does Spain compare?, in: OECD Employment Outlook 2012, OECD, Paris.

Ours, J.C. van (1991), The efficiency of the dutch labour market in matching unemployment and vacancies, De Economist, 139 , pp. 358-378.

Ours, J.C. van (2003), Has the Dutch miracle come to an end?, CESIFO Working Paper, no. 917.

Petrongolo, B. and C.A. Pissarides (2001), Looking into the black box: A survey of the matching function, Journal of Economic Literature, pp. 390-431.

Pissarides, C. (2001), Steady-state Unemployment Theory, MIT Press, $2^{\text {nd }}$ edition Cambridge (Mass.).

Rothstein, J. (2011), Unemployment insurance and job search in the Great Recession, National Bureau of Economic Research, NBER Working Paper, no. w17534, Cambridge (Mass.).

Şahin, A., J. Song, G. Topa and G.L. Violante (2014), Mismatch unemployment, American Economic Review, 104(11), pp. 3529-3564.

Sedláček, P. (2014), Match efficiency and firms' hiring standards, Journal of Monetary Economics, 62, pp. 123-133.

Shibata, M.I. (2013), Is labor market mismatch a big deal in Japan?, International Monetary Fund, Discussion paper no. 13-196.

Shimer, R. (2012), Reassessing the ins and outs of unemployment, Review of Economic Dynamics, 15(2), pp. 127-148.

Shimer, R. (2005), The cyclical behavior of equilibrium unemployment and vacancies, American Economic Review, 95(1), pp. 25-49. 
Smith, J.C. (2011), The ins and outs of UK unemployment, The Economic Journal, 121(552), pp. 402-444. Spletzer, J.R. (1997), Re-examining the added worker effect, Economic Inquiry, 35(2), pp. 417-427.

Sterk, V. (2010), Home equity, mobility, and macroeconomic fluctuations, DNB Working Paper, no. 265, Amsterdam.

UWV (2014), Financiële dienstverlening. Sectorbeschrijving, Amsterdam.

Valletta, R.G. and K. Kuang (2010), Is structural unemployment on the rise?, FRBSF Economic Letter, 34.

Valletta, R.G. (2013), House lock and structural unemployment, Labour Economics, 25, pp. 86-97.

Veracierto, M. (2011), Worker flows and matching efficiency, Federal Reserve Bank of Chicago, Economic Perspectives, 35(4), pp. 147-169. 


\section{Appendix}

\section{A.1 Hire rate and growth rate of employment expressed in terms of vacancies}

To express the hire rate $h_{t}$ in terms of the number vacancies, we first denote:

$h_{t}=\frac{H_{t}}{E_{t-1}}$

where $H_{t}$ are the amount of hires in a quarter and $E_{t-1}$ represents the number of employed at the beginning of the quarter. Next, we write:

$\frac{H_{t}}{E_{t-1}}=\frac{E_{t}}{E_{t-1}} \frac{E_{t}+V_{t}}{E_{t}} \frac{V_{t}}{E_{t}+V_{t}} \frac{H_{t}}{V_{t}}=\left(1+g_{t}^{(e)}\right) \frac{v_{t}}{1-v_{t}} h_{t}$

where $V_{t}$ represents the number of vacancies in quarter $t$. Equation (A.2) gives us the hire rate in terms of the vacancy rate and the vacancy yield, i.e. the number of hires per vacancy.

Barnichon et al. (2012) define the lay-off rate as $l_{t}=\frac{L_{t}}{E_{t}}$ and the quit rate as $q_{t}=\frac{Q_{t}}{E_{t}}$. In our case we have information on the separation rate $S_{t}=L_{t}+Q_{t}$. Therefore we define $s_{t}=\frac{L_{t}+Q_{t}}{E_{t}}=l_{t}+q_{t}$. Now we can express $g_{t}^{(e)}$ as an implicit function of $h_{t}$ and $s_{t}$ and write:

$g_{t}^{(e)}=\frac{E_{t}-E_{t-1}}{E_{t-1}}=\frac{H_{t}-S_{t}}{E_{t-1}}=\frac{H_{t}}{E_{t-1}}-\frac{E_{t}}{E_{t-1}} s_{t}=\left(1+g_{t}^{(e)}\right) \frac{v_{t}}{1-v_{t}} h_{t}-s_{t}$

Solving this expression leads to an explicit expression for $g_{t}^{(e)}$

$g_{t}^{(e)}=\frac{\frac{v_{t}}{1-v_{t}} h_{t}-s_{t}}{1-\frac{v_{t}}{1-v_{t}} h_{t}+s_{t}}$

\section{A.2 Steady-state Beveridge curve}

The steady-state Beveridge curve can be determined by setting the growth rate of the labour force equal to the growth rate of employment:

$0=g_{t}^{(l f)}-g_{t}^{(e)}$

Substitution of equation (2) and (A.5) gives

$0=\eta_{t}-\chi_{t}-\frac{\frac{v_{t}}{1-v_{t}} h_{t}-s_{t}}{1-\frac{v_{t}}{1-v_{t}} h_{t}+s_{t}}$

Taking the exponent of equation (7) and substituting the estimated parameters, assuming $\varepsilon_{t}=0$ and replacing the unemployment rate $u_{t}$ with the unknown steady-state employment rate $u^{*}$ gives:

$\hat{\eta}_{t}=e^{\widehat{\beta}^{\eta}}\left(\frac{v_{t}}{u^{*}}\right)^{\hat{\alpha}^{\eta}}$

$\hat{\chi}_{t}=e^{\widehat{\beta}^{\chi}}\left(\frac{v_{t}}{u^{*}}\right)^{\hat{\alpha}^{\chi}}$

$\hat{h}_{t}=e^{\widehat{\beta}^{h}}\left(\frac{v_{t}}{u^{*}}\right)^{\widehat{\alpha}^{h}}$ 
$\hat{s}_{t}=e^{\widehat{\beta}^{s}}\left(\frac{v_{t}}{u^{*}}\right)^{\widehat{\alpha}^{s}}$

(A.7 to A.10) can be substituted in (A.6) giving:

$0=e^{\widehat{\beta}^{\eta}}\left(\frac{v_{t}}{u^{*}}\right)^{\widehat{\alpha}^{\eta}}-e^{\widehat{\beta}^{\chi}}\left(\frac{v_{t}}{u^{*}}\right)^{\widehat{\alpha}^{\chi}}-\frac{\frac{v_{t}}{1-v_{t}} e^{\widehat{\beta}^{h}}\left(\frac{v_{t}}{u^{*}}\right)^{\widehat{\alpha}^{h}}-e^{\widehat{\beta}^{s}}\left(\frac{v_{t}}{u^{*}}\right)^{\widehat{\alpha}^{s}}}{1-\frac{v_{t}}{1-v_{t}} e^{\widehat{\beta}^{h}}\left(\frac{v_{t}}{u^{*}}\right)^{\widehat{\alpha}^{h}}+e^{\widehat{\beta}^{s}}\left(\frac{v_{t}}{u^{*}}\right)^{\widehat{\alpha}^{s}}}$

\section{A.3 Calculating the mismatch index}

We calculate the mismatch index according to the definition given by Şahin et al. (2014) and Marthin (2012). Mismatch describes the gap between the counterfactual amount hires and the actual amount of hires. The latter is given by:

$H_{t}=\Phi \sum_{i=1}^{I} \phi_{i} V_{i, t}{ }^{\alpha} U_{i, t}{ }^{1-\alpha}=\left(\frac{V_{t}}{V_{t}}\right)^{\alpha}\left(\frac{U_{t}}{U_{t}}\right)^{1-\alpha} \Phi \sum_{i=1}^{I} \phi_{i} V_{i, t}{ }^{\alpha} U_{i, t}{ }^{1-\alpha}$
$=\Phi V_{t}^{\alpha} U_{t}^{1-\alpha} \cdot\left[\sum_{i=1}^{I} \phi_{i}\left(\frac{V_{i, t}}{V_{t}}\right)^{\alpha}\left(\frac{U_{i, t}}{U_{t}}\right)^{1-\alpha}\right]$

For the counterfactual amount of hires we can substitute equation (12) in equation (A.12) and multiply by $\left(\frac{\varphi_{i}{ }^{1 / \alpha}}{\varphi_{i}{ }^{1 / \alpha}}\right)^{\alpha}$.

$H_{t}^{*}=\Phi V_{t}^{\alpha} U_{t}^{1-\alpha} \cdot\left[\sum_{i=1}^{I} \phi_{i}\left(\frac{V_{i, t}}{V_{t}}\right)^{\alpha}\left(\phi_{i}^{\frac{1}{\alpha}} \cdot \frac{V_{i, t}}{\sum_{i=1}^{I}\left(V_{i, t} \phi_{i}^{\frac{1}{\alpha}}\right)}\right)^{1-\alpha}\right]$

$=\Phi V_{t}^{\alpha} U_{t}^{1-\alpha} \cdot\left[\sum_{i=1}^{I} \phi_{i}\left(\frac{\sum_{i=1}^{I}\left(V_{i, t} \phi_{i}^{\frac{1}{\alpha}}\right)}{V_{t}}\right)^{\alpha}\left(\frac{1}{\phi_{i}^{\frac{1}{\alpha}}}\right)^{\alpha}\left(\phi_{i}^{\frac{1}{\alpha}} \cdot \frac{V_{i, t}}{\sum_{i=1}^{I}\left(V_{i, t} \phi_{i}^{\frac{1}{\alpha}}\right)}\right)\right]$

Now $\left(\sum_{i=1}^{I} V_{i, t} \phi_{i}^{\frac{1}{\alpha}} \frac{V_{i, t}}{V_{t}}\right)^{\alpha}$ can be represented as $\overline{x_{t}}$ and equation (A.13) can be multiplied by $\frac{V_{t}}{V_{t}}$. This leads to:

$H_{t}^{*}=\Phi V_{t}^{\alpha} U_{t}^{1-\alpha} \cdot\left[\overline{x_{t}} \sum_{i=1}^{I}\left(\phi_{i}^{\frac{1}{\alpha}} \cdot \frac{V_{i, t}}{\sum_{i=1}^{I}\left(V_{i, t} \phi_{i}^{\frac{1}{\alpha}}\right)}\right)\right]=\Phi V_{i, t}^{\alpha} U_{i, t}^{1-\alpha} \cdot\left[\overline{x_{t}} \frac{\sum_{i=1}^{I} \phi_{i}^{\frac{1}{\alpha}\left(\frac{V_{i, t}}{V_{t}}\right)}}{\sum_{i=1}^{I} \phi_{i}^{\frac{1}{\alpha}\left(\frac{V_{i, t}}{V_{t}}\right)}}\right]=\Phi V_{t}^{\alpha} U_{t}^{1-\alpha} \bar{\phi}_{t}$

where $\bar{\phi}_{t}=\bar{x}_{t}$.

The mismatch index is the number of failed hires, expressed as a fraction of the counterfactual amount of hires:

$$
\begin{aligned}
& M_{t}=1-\frac{H_{t}}{H_{t}^{*}}=1-\frac{\Phi_{\mathrm{t}} V_{t}^{\alpha} U_{t}^{1-\alpha}\left[\sum_{i=0}^{I} \phi_{i}\left(\frac{V_{i, t}}{V_{t}}\right)^{\alpha}\left(\frac{U_{i, t}}{U_{t}}\right)^{1-\alpha}\right]}{\Phi_{\mathrm{t}} V_{t}^{\alpha} U_{t}^{1-\alpha} \bar{\phi}_{t}} \\
& =1-\sum_{i=0}^{I}\left(\frac{\phi_{i}}{\overline{\phi_{t}}}\right)\left(\frac{V_{i, t}}{V_{t}}\right)^{\alpha}\left(\frac{U_{i, t}}{U_{t}}\right)^{1-\alpha}
\end{aligned}
$$

We obtain estimates of our model parameters by estimating the following panel regression: 
$\ln \left(\frac{H_{i, t}}{U_{i, t}}\right)=c+\ln \left(\Phi_{t}\right)+\ln \left(\varphi_{i}\right)+\alpha \ln \left(\frac{V_{i, t}}{U_{i, t}}\right)+\varepsilon_{t}$

\section{A.4 Sector classification}

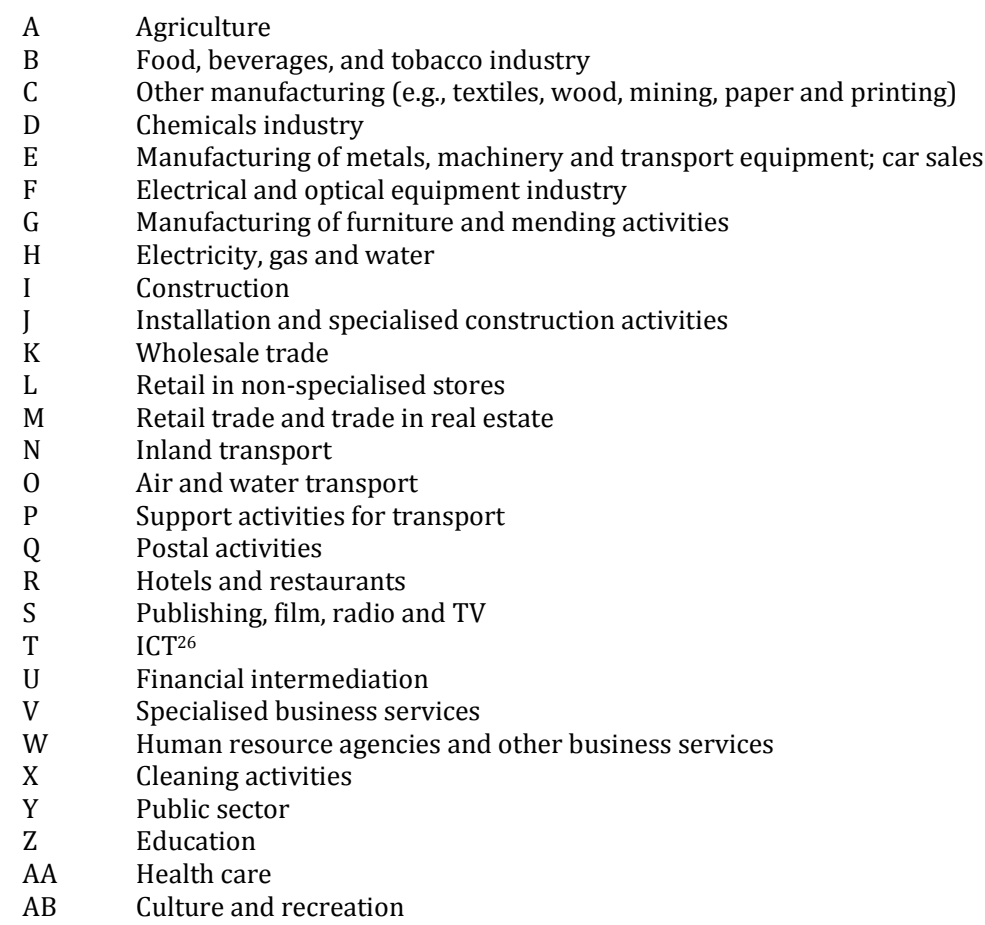

\section{A.5 Macro estimation results, total sample, and crisis sample}

This appendix shows the estimation results of the three-state labour market model based on equation (7) for our total sample period and the pre-crisis period. These results are used to derive steady-state curves based on different samples in order to test the robustness of the curve based on the totale sample.

\section{Table A.1 Estimation results}

\begin{tabular}{|c|c|c|c|c|}
\hline & Separation rate & Vacancy yield & Labour force exit & Labour force entry \\
\hline & $\ln \left(s_{t}\right)$ & $\ln \left(h_{t}\right)$ & $\ln \left(\chi_{t}\right)$ & $\ln \left(\eta_{t}\right)$ \\
\hline Constant $(\beta)$ & $-3.62^{* * *}$ & $-0.15^{* * *}$ & $-3.43^{* * *}$ & $-3.27^{* * *}$ \\
\hline $\ln \left(v_{t} / u_{t}\right)(\alpha)$ & $-0.117^{* * *}$ & $-0.570^{* * *}$ & $-0.078^{* * *}$ & 0.016 \\
\hline $\mathrm{R}^{2}$ & 0.41 & 0.92 & 0.53 & 0.02 \\
\hline S.E. & 0.07 & 0.08 & 0.03 & 0.05 \\
\hline $\mathrm{N}$ (observations) & 23 & 23 & 23 & 23 \\
\hline \multicolumn{5}{|c|}{ Crisis sample (2008Q4-2013Q4) } \\
\hline & Separation rate & Vacancy yield & Labour force exit & Labour force entry \\
\hline & $\ln \left(s_{t}\right)$ & $\ln \left(h_{t}\right)$ & $\ln \left(\chi_{t}\right)$ & $\ln \left(\eta_{t}\right)$ \\
\hline Constant $(\beta)$ & $-3.48^{* * *}$ & -0.06 & $-3.52^{* * *}$ & $-3.44^{* * *}$ \\
\hline $\ln \left(v_{t} / u_{t}\right)(\alpha)$ & $-0.13^{* * *}$ & $-0.59^{* * *}$ & $-0.19^{* * *}$ & $-0.13^{* * *}$ \\
\hline $\mathrm{R}^{2}$ & 0.53 & 0.94 & 0.78 & 0.49 \\
\hline S.E. & 0.06 & 0.07 & 0.05 & 0.06 \\
\hline N (observations) & 21 & 21 & 21 & 21 \\
\hline
\end{tabular}

HAC standard errors and covariance. Significant at * $10 \% ; * * 5 \% ; * * * 1 \%$.

\footnotetext{
${ }^{26}$ With regard to the sector information and communication $(\mathrm{J})$, we have to adjust the data, as vacancies are published for this sector, whereas the number of unemployment beneficiaries is only available for the communications sector (i.e. publishing and telecommunications). In the database of UWV, all activities regarding the IT sector are included in the specialised business services industry. We use data from the national accounts to calculate the share of persons employed in the IT sector (i.e. support activities in the field of information technology (62) and Information service activities (63)) within the sector Consultancy, research and other specialised business services (M)). Next, we use this share as a proxy to separate the number of unemployment beneficiaries in the IT sector from the business services sector in the UWV data and add this amount to the communications sector.
} 


\section{A.6 Structural break analysis}

Testing for a structural break in the steady-state curves for the pre-crisis and post-crisis sample is not straightforward. This is due to the fact that our derived steady-state Beveridge curve is the exact solution of equation (8). Therefore we do not have residuals, and we cannot apply a Chow-test. Since we do not estimate the curve, it is not possible to use Maximum Likelihood methods in order to conduct likelihood ratio tests.

When inspecting the solutions of equation (8), it turns out that all derived Beveridge curves follow an exact power function:

$v=a u^{b} \leftrightarrow \log v=\log (a)+b \cdot \log u=c+b \cdot \log u$

If a structural break exists, $c_{\text {pre }} \neq c_{\text {crisis }}$ and/or $b_{\text {pre }} \neq b_{\text {crisis }}$. Therefore we define $c_{\text {diff }}=c_{\text {crisis }}-c_{\text {pre }}$ and $b_{\text {diff }}=b_{\text {crisis }}-b_{\text {pre }}$ and test whether $c_{\text {diff }}=0$ and/or $b_{\text {diff }}=0$. We do this by bootstrapping the distribution of $c_{\text {diff } f}$ and $b_{\text {diff } f}$. We draw a bootstrap sample one thousand times of both the pre-crisis (i.e. 2003Q1-2008Q3) and the crisis period (2008Q4-2013Q4) and perform the regressions of equation (7).

Each time we solve equation (8) for both periods, we obtain parameters $b_{\text {pre }}, b_{c r i s i s}, c_{p r e}$ and $c_{c r i s i s}$ (the confidence intervals of the pre-crisis and crisis curves are shown in the Figure A.1). We calculate $b_{\text {diff }}$ and $c_{\text {diff }}$. Using the thousand obtained samples of $b_{\text {diff }}$ and $c_{\text {diff }}$ we calculate the $95 \%$-confidence interval. In both cases the confidence interval includes zero. In addition, we perform a test on both parameters simultaneously by obtaining the $95 \%$-confidence ellipse. We approximate this ellipse by assuming that $b_{\text {diff }}$ and $c_{\text {diff }}$ are distributed according to a bivariate normal distribution and conclude that $b_{\text {diff }}=$ $0, c_{\text {diff }}=0$ falls within the $95 \%$ confidence interval. This indicates no structural break as well.

\section{Figure A.1 Structural break analysis}

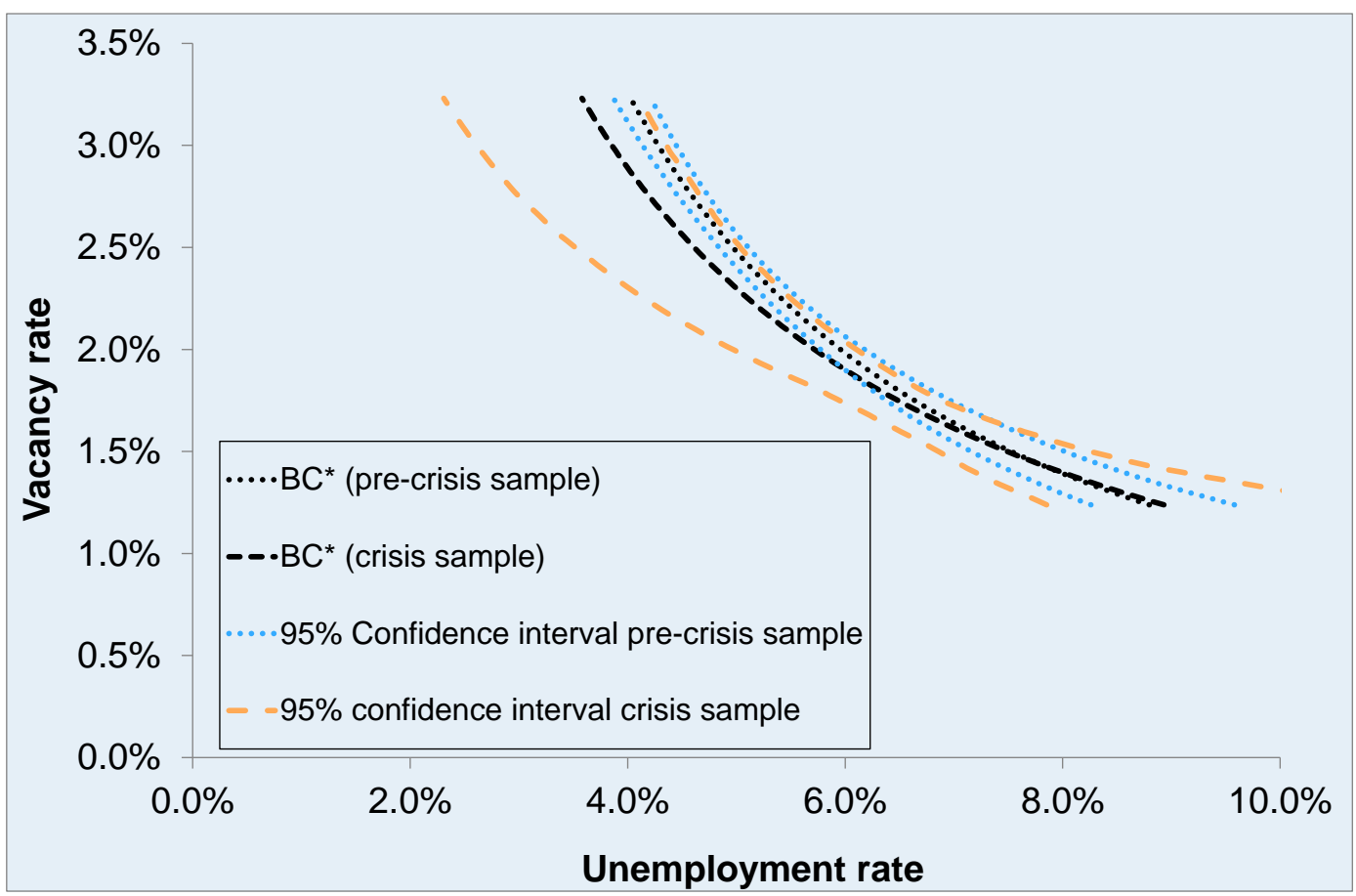

\section{A.7 Recovery path from the Great Recession}

The deviation from the steady-state curve is given by $\Delta v_{t}=\left|v_{t}-v^{*}\right|$. Deviations from the steady-state curve during the last recovery phase $(2004 \mathrm{Q} 2-2008 \mathrm{Q} 3)$ will provide the fundamentals for our recovery path. Since the peak in unemployment differs between each crisis, we scale the observed unemployment 
rates linearly to range from the equilibrium unemployment $u_{e q}$ (the lowest observed unemployment rate) to the expected return point $\hat{u}_{r}$, which we define by the unemployment prediction where $\hat{u}_{t}<\hat{u}_{t-1}$ and $\hat{u}_{t-1}>\hat{u}_{t-2}$, instead. Next, the following curve is fitted:

$\Delta v_{t}=\frac{a \cdot u^{2}+b \cdot u+c}{u}=a \cdot u+b+\frac{c}{u}$

This curve has two constraints. First of all, the deviation of $v_{t}$ at the (forecasted) return point $\hat{u}_{r}$ is constrained at 0 . Furthermore the deviation of $v_{t}$ at the steady-state unemployment $u_{e q}$ is constrained at 0 . Now we minimise the Sum of Squared Errors with respect to the parameters $a, b$ and $c$, given these constraints. This optimisation problem is given by:

$\min _{a, b, c} \sum_{t=1}^{T}\left(v_{t}-a \cdot u+b+\frac{c}{u}\right)^{2}$

$v_{r}-a \cdot \hat{u}_{r}+b+\frac{c}{\hat{u}_{r}}=0$
subject to
$v_{e q}-a \cdot u_{e q}+b+\frac{c}{u_{e q}}=0$

and solved using a GRG2 method. The corresponding Beveridge curve vacancy rate $\left(\hat{v}_{t}\right)$ is calculated and the expected deviation $\widehat{\Delta v}_{t}$ is added. We have also estimated a curve using pre- and crisis observations without scaling. The results from this analysis only differ marginally from the path illustrated in Figure 4.

\section{A.8 Intrasectoral mismatch}

If vacancies and the unemployed are distributed unevenly across segments of the economy (i.e. sectors, occupations, regions), mismatch might not be visible in our macro analysis, but could be present within the economy. Consequently, it is recommendable to examine mismatch on a lower level of aggregation. In Section 2.2 we regarded mismatch between sector using a mismatch index. In this appendix, we will deal with mismatch within sectors. This is done by deriving steady-state Beveridge curves for 28 individual sectors and compare the most recent data on the $v_{t}$ and $u_{t}$-rates with these steady-state Beveridge curves. As we lack data on the entry and exits from the labour force, we have to rely on a two-state labour market model to derive our sector steady-state Beveridge curves.

\section{Two-state labour market model}

In a two-state labour market, changes in the unemployment rate are caused by people exiting employment at rate $s_{t}$ and by unemployed workers finding a job at rate $f_{t}$ (Shimer, 2012).

$\Delta u_{t}=s_{t}\left(1-u_{t}\right)-f_{t} u_{t}$

We follow Fujita and Ramey (2009) and define the separation rate $\left(s_{t}\right)$ as all transitions from employment to unemployment (i.e. all separations) during period $t$ as a fraction of employment at the beginning of period $t$. The job-finding rate $\left(f_{t}\right)$ is defined as the outflow of people from unemployment to employment in period $t$ as a fraction of unemployment at the beginning of period $t$. Next, the unemployment rate is in its steady state when inflows equal outflows (i.e. $\Delta u_{t}=0$ ).

$u_{t}^{*}=\frac{s_{t}}{s_{t}+f_{t}}$

To relate the steady-state condition in equation (A.20) to the Beveridge curve, we link both the separation rate $\left(s_{t}\right)$ and job-finding rate $\left(f_{t}\right)$ to the $v_{t} / u_{t}$-ratio:

$$
\begin{aligned}
& \ln \left(s_{t}\right)=\beta^{s}+\alpha^{s} \ln \left(\frac{v_{t}}{u_{t}}\right)+\varepsilon_{t} \\
& \ln \left(f_{t}\right)=\beta^{f}+\alpha^{f} \ln \left(\frac{v_{t}}{u_{t}}\right)+\varepsilon_{t}
\end{aligned}
$$


Next, after taking exponents, we substitute the estimates of $s_{t}$ and $f_{t}$ from equations (A.22) and (A.23) into the steady-state condition of the unemployment rate (i.e. setting $\Delta u_{t}=0$ in equation (A.20)):

$0=e^{\widehat{\beta}^{s}}\left(\frac{v_{t}}{u_{t}}\right)^{\widehat{\alpha}^{S}}\left(1-u_{t}\right)-e^{\widehat{\beta}^{f}}\left(\frac{v_{t}}{u_{t}}\right)^{\widehat{\alpha}^{f}} u_{t}$

Equation (A.24) links the steady-state condition of the unemployment rate to the vacancy and unemployment space of the Beveridge curve. Hence, equation (A.24) describes the set of combinations of $v_{t}$ and $u_{t}$ for which unemployment is in its steady state. Figure A.4 shows that unemployment dynamics are quite accurately approximated by the steady-state value of the two-state model, the three-state model described in Section 2.1 gives a better estimate of actual unemployment.

\section{Estimation results}

We estimate equations (A.22) and (A.23) for 28 sectors covering the period 1999-2013, i.e. 15 data points per sector. Table A. 2 in shows the estimation results. The estimations show that on the sector level, the correlation between labour market tightness and the exit rate (indicated by the $\alpha$ ) is weak. This is contrary to the results of Barnichon et al. (2012), who find a clear correlation on the sector level between the vacancy yield (hires per vacancy) on the one hand and the $v_{t} / u_{t}$-ratio as an indicator of labour market tightness on the other hand. Most likely, the weak correlation is caused by the fact that we use exit rates instead of hire rates or the vacancy yield. Besides hires, our exit rate also includes flows from unemployment benefits to non-participation, which seems to be less likely correlated with labour market tightness. Think, for instance, of the older unemployed, who use unemployment benefits as means to flow into retirement. The separation rate $\left(s_{t}\right)$ seems to have a much stronger correlation with labour market tightness. Except for wholesale trade (K), non-specialised retail (L), water and air transport (O), financial intermediation $(\mathrm{U})$, and the public sector $(\mathrm{Y})$, there is a significant negative correlation between the separation rate and labour market tightness. This means that if the labour market tightens within a sector, the amount of separations drop, as employers tend to hold on to their workers. Vice versa, a labour market that is coping with increasing slack will be accompanied by a larger degree of separations.

\section{Steady-state BC per sector}

Our steady-state condition imposes that the number of people who receive unemployment benefits is constant. Consequently, we have to equate the number of separations to the number of job finders (in our case, the number of exits from unemployment benefit schemes). We solve equation (A.24) using the coefficients from Table A.2 to obtain the steady-state Beveridge curves for the individual sectors. Figure A.2 shows the results, with the orange solid lines representing the steady-state Beveridge curves. The pattern highlighted by the blue line in Figure A.2 shows the Beveridge curve development during the previous cycle. The previous cycle for each individual sector is defined as the unemployment rate from through to through. For many sectors this encompasses the period 2001 until 2008.

Persistent deviations from both the steady-state curve, as well as the anti-clockwise pattern, can be regarded as signs of increasing mismatch within the sector. This might be related to skills, occupational or geographical mismatch. Due to limited data availability, we are not able to draw recovery paths for individual sectors, comparable to the path we drew for the total economy in Figure 4.

There are a number of conclusions that we can draw from Figure A.2. First, in all 28 sectors examined, somewhat less than half of the sectors reveal $v_{t} / u_{t}$-ratios in 2014 that lie on or close to the calculated steady-state Beveridge curve. Second, if we take the anti-clockwise pattern (blue line) during the previous cycle into consideration, most of the sectors that do show deviations from the steady-state curve also displayed large deviations during the previous economic cycle, without an actual shift of the steady-state Beveridge curve. Within four sectors does the $v_{t} / u_{t}$-ratio in 2014 depict a large divergence from the previous cycle, as well as the Beveridge curve. These four sectors are: financial intermediation; postal activities; publishing, film, radio and TV; and cleaning activities. With regard to the latter two sectors, the 2014 observation does not fit into a clear pattern of outward movement of the unemployment-vacancy locus over a longer time span. Based on one observation, it is too early to conclude that the effectiveness and speed of the matching process within these sectors has been damaged. 
Table A.2 Estimation results two-state labour market model

\begin{tabular}{|c|c|c|c|c|c|c|c|}
\hline Sector & & $\ln \left(e_{t}\right)$ & $\ln \left(S_{t}\right)$ & Sector & & $\ln \left(e_{t}\right)$ & $\ln \left(s_{t}\right)$ \\
\hline \multirow[t]{4}{*}{ Agriculture (A) } & $\beta$ [constant] & $0.55^{* * *}$ & $-3.19^{* * *}$ & Water and air transport $(\mathrm{O})$ & $\beta$ [constant] & $0.35^{* * *}$ & $-3.49^{* * *}$ \\
\hline & $\alpha\left[\ln \left(v_{t, i} / u_{t, i}\right)\right]$ & -0.09 & $-0.52^{* * * *}$ & & $\alpha\left[\ln \left(v_{t, i} / u_{t, i}\right)\right]$ & 0.03 & -0.13 \\
\hline & $\mathrm{R}^{2}$ & 0.04 & 0.54 & & $\mathrm{R}^{2}$ & 0.02 & 0.21 \\
\hline & $\mathrm{N}$ & 14 & 14 & & $\mathrm{~N}$ & 14 & 14 \\
\hline \multirow[t]{4}{*}{ Food, beverages, and tobacco (B) } & $\beta$ [constant] & 0.15 & $-3.39^{* * *}$ & Support activities for transport (P) & $\beta$ [constant] & $0.28^{* *}$ & $-3.10^{* * *}$ \\
\hline & $\alpha\left[\ln \left(v_{t, i} / u_{t, i}\right)\right]$ & 0.07 & $-0.29^{*}$ & & $\alpha\left[\ln \left(v_{t, i} / u_{t, i}\right)\right]$ & 0.06 & $-0.36^{*}$ \\
\hline & $\mathrm{R}^{2}$ & 0.03 & 0.48 & & $R^{2}$ & 0.01 & 0.27 \\
\hline & $\mathrm{N}$ & 14 & 14 & & $\mathrm{~N}$ & 14 & 14 \\
\hline \multirow[t]{4}{*}{ Other manufacturing $(\mathrm{C})$} & $\beta$ [constant] & -0.03 & $-3.65^{* * * *}$ & Postal services (Q) & $\beta$ [constant] & -0.16 & $-4.55^{* * *}$ \\
\hline & $\alpha\left[\ln \left(v_{t, i} / u_{t, i}\right)\right]$ & 0.00 & $-0.50^{* * *}$ & & $\alpha\left[\ln \left(v_{t, i} / u_{t, i}\right)\right]$ & 0.02 & $-0.42^{*}$ \\
\hline & $\mathrm{R}^{2}$ & 0.00 & 0.68 & & $\mathrm{R}^{2}$ & 0.00 & 0.25 \\
\hline & $\mathrm{N}$ & 14 & 14 & & $\mathrm{~N}$ & 14 & 14 \\
\hline \multirow[t]{4}{*}{ Chemicals industry (D) } & $\beta$ [constant] & -0.13 & $-3.45^{* * *}$ & Hotels and restaurants (R) & $\beta$ [constant] & $0.41^{* * * *}$ & $-3.22^{* * * *}$ \\
\hline & $\alpha\left[\ln \left(v_{t, i} / u_{t, i}\right)\right]$ & 0.02 & $-0.33^{* *}$ & & $\alpha\left[\ln \left(v_{t, i} / u_{t, i}\right)\right]$ & 0.06 & $-0.40^{* * *}$ \\
\hline & $\mathrm{R}^{2}$ & 0.00 & 0.35 & & $\mathrm{R}^{2}$ & 0.03 & 0.50 \\
\hline & $\mathrm{N}$ & 14 & 14 & & $\mathrm{~N}$ & 14 & 14 \\
\hline \multirow[t]{4}{*}{ Metals, machinery, transport eq. (E) } & $\beta$ [constant] & $0.34^{* *}$ & $-3.63^{* * *}$ & Publishing, film, radio and TV (S) & $\beta$ [constant] & $0.15^{* * *}$ & $-3.07^{* * *}$ \\
\hline & $\alpha\left[\ln \left(v_{t, i} / u_{t, i}\right)\right]$ & 0.00 & $-0.43^{* * *}$ & & $\alpha\left[\ln \left(v_{t, i} / u_{t, i}\right)\right]$ & $0.13^{* *}$ & $-0.48^{* * *}$ \\
\hline & $\mathrm{R}^{2}$ & 0.00 & 0.53 & & $\mathrm{R}^{2}$ & 0.38 & 0.75 \\
\hline & $\mathrm{N}$ & 14 & 14 & & $\mathrm{~N}$ & 14 & 14 \\
\hline \multirow[t]{4}{*}{ Electrical and optical equipment (F) } & $\beta$ [constant] & $-0.26^{* * *}$ & $-3.09^{* * *}$ & ICT (T) & $\beta$ [constant] & $0.34^{* * *}$ & $-2.83^{* * *}$ \\
\hline & $\alpha\left[\ln \left(v_{t, i} / u_{t, i}\right)\right]$ & 0.10 & $-0.36^{* *}$ & & $\alpha\left[\ln \left(v_{t, i} / u_{t, i}\right)\right]$ & $0.13^{*}$ & $-0.36^{* * *}$ \\
\hline & $\mathrm{R}^{2}$ & 0.06 & 0.46 & & $\mathrm{R}^{2}$ & 0.24 & 0.60 \\
\hline & $\mathrm{N}$ & 14 & 14 & & $\mathrm{~N}$ & 14 & 14 \\
\hline \multirow[t]{4}{*}{ Furniture and mending (G) } & $\beta$ [constant] & $0.28^{* *}$ & $-2.12^{* * *}$ & Financial intermediation (U) & $\beta$ [constant] & $-0.12^{* *}$ & $-3.35^{* * *}$ \\
\hline & $\alpha\left[\ln \left(v_{t, i} / u_{t, i}\right)\right]$ & 0.03 & $-0.54^{* * *}$ & & $\alpha\left[\ln \left(v_{t, i} / u_{t, i}\right)\right]$ & 0.09 & -0.30 \\
\hline & $\mathrm{R}^{2}$ & 0.00 & 0.68 & & $\mathrm{R}^{2}$ & 0.07 & 0.12 \\
\hline & $\mathrm{N}$ & 14 & 14 & & $\mathrm{~N}$ & 14 & 14 \\
\hline \multirow[t]{4}{*}{ Utilities (H) } & $\beta$ [constant] & -0.16 & $-3.49^{* * *+1}$ & Specialised business services (V) & $\beta$ [constant] & $0.41^{* * *}$ & $-2.99^{* * *}$ \\
\hline & $\alpha\left[\ln \left(v_{t, i} / u_{t, i}\right)\right]$ & $0.28^{*}$ & $-0.43^{* *}$ & & $\alpha\left[\ln \left(v_{t, i} / u_{t, i}\right)\right]$ & 0.10 & $-0.39^{* * * *}$ \\
\hline & $\mathrm{R}^{2}$ & 0.32 & 0.43 & & $\mathrm{R}^{2}$ & 0.14 & 0.60 \\
\hline & $\mathrm{N}$ & 14 & 14 & & $\mathrm{~N}$ & 14 & 14 \\
\hline \multirow[t]{4}{*}{ Construction (I) } & $\beta$ [constant] & $0.69^{* * *}$ & $-2.81^{* * *}$ & $\begin{array}{l}\text { HR agencies, other business } \\
\text { services (W) }\end{array}$ & $\beta$ [constant] & $0.96^{* * *}$ & $-2.04^{* * * *}$ \\
\hline & $\alpha\left[\ln \left(v_{t, i} / u_{t, i}\right)\right]$ & 0.06 & $-0.39^{* * * *}$ & & $\alpha\left[\ln \left(v_{t, i} / u_{t, i}\right)\right]$ & $0.13^{* *}$ & $-0.31^{* * *}$ \\
\hline & $\mathrm{R}^{2}$ & 0.05 & 0.67 & & $\mathrm{R}^{2}$ & 0.30 & 0.66 \\
\hline & $\mathrm{N}$ & 14 & 14 & & $\mathrm{~N}$ & 14 & 14 \\
\hline \multirow[t]{4}{*}{ Specialised construction $(\mathrm{J})$} & $\beta$ [constant] & $0.67^{* * *}$ & $-1.47^{* * *}$ & Cleaning activities $(\mathrm{X})$ & $\beta$ [constant] & $0.47^{* * *}$ & $-3.12^{* * *}$ \\
\hline & $\alpha\left[\ln \left(v_{t, i} / u_{t, i}\right)\right]$ & 0.02 & $-0.49^{* * *}$ & & $\alpha\left[\ln \left(v_{t, i} / u_{t, i}\right)\right]$ & 0.14 & $-0.39^{* *}$ \\
\hline & $\mathrm{R}^{2}$ & 0.02 & 0.77 & & $\mathrm{R}^{2}$ & 0.14 & 0.41 \\
\hline & $\mathrm{N}$ & 14 & 14 & & $\mathrm{~N}$ & 14 & 14 \\
\hline \multirow[t]{4}{*}{ Wholesale trade $(\mathrm{K})$} & $\beta$ [constant] & $0.25^{* * *}$ & $-3.14^{* * *}$ & Public sector $(\mathrm{Y})$ & $\beta$ [constant] & $0.26^{* * *}$ & $-4.23^{* *}$ \\
\hline & $\alpha\left[\ln \left(v_{t, i} / u_{t, i}\right)\right]$ & 0.03 & -0.48 & & $\alpha\left[\ln \left(v_{t, i} / u_{t, i}\right)\right]$ & 0.14 & -0.15 \\
\hline & $\mathrm{R}^{2}$ & 0.01 & 0.65 & & $\mathrm{R}^{2}$ & 0.20 & 0.15 \\
\hline & $\mathrm{N}$ & 14 & 14 & & $\mathrm{~N}$ & 11 & 11 \\
\hline \multirow[t]{4}{*}{ Retail trade, non-specialised (L) } & $\beta$ [constant] & $0.63^{* * *}$ & $-3.50^{* * *}$ & Education (Z) & $\beta$ [constant] & $0.48^{* * *}$ & $-3.81^{* * *}$ \\
\hline & $\alpha\left[\ln \left(v_{t, i} / u_{t, i}\right)\right]$ & 0.15 & -0.17 & & $\alpha\left[\ln \left(v_{t, i} / u_{t, i}\right)\right]$ & 0.09 & $-0.33^{* * *}$ \\
\hline & $\mathrm{R}^{2}$ & 0.16 & 0.11 & & $R^{2}$ & 0.22 & 0.84 \\
\hline & $\mathrm{N}$ & 14 & 14 & & $\mathrm{~N}$ & 11 & 14 \\
\hline \multirow[t]{4}{*}{ Retail trade, trade in real estate (M) } & $\beta$ [constant] & $0.47^{* n+}$ & $-3.01^{* * * *}$ & Health care (AA) & $\beta$ [constant] & $0.25^{* * *}$ & $-3.70^{* * *}$ \\
\hline & $\alpha\left[\ln \left(v_{t, i} / u_{t, i}\right)\right]$ & 0.10 & $-0.48^{* * *}$ & & $\alpha\left[\ln \left(v_{t, i} / u_{t, i}\right)\right]$ & 0.03 & $-0.53^{* * *}$ \\
\hline & $\mathrm{R}^{2}$ & 0.06 & 0.60 & & $\mathrm{R}^{2}$ & 0.00 & 0.56 \\
\hline & $\mathrm{N}$ & 14 & 14 & & $\mathrm{~N}$ & 14 & 14 \\
\hline \multirow[t]{4}{*}{ Inland transport (N) } & $\beta$ [constant] & $0.25^{* *}$ & $-3.51^{* * *}$ & Culture and recreation (AB) & $\beta$ [constant] & $0.46^{* * * *}$ & $-2.31^{* * *}$ \\
\hline & $\alpha\left[\ln \left(v_{t, i} / u_{t, i}\right)\right]$ & -0.05 & $-0.44^{* * *}$ & & $\alpha\left[\ln \left(v_{t, i} / u_{t, i}\right)\right]$ & 0.09 & $-0.28 * * *$ \\
\hline & $\mathrm{R}^{2}$ & 0.04 & 0.72 & & $\mathrm{R}^{2}$ & 0.17 & 0.53 \\
\hline & $\mathrm{N}$ & 14 & 14 & & $\mathrm{~N}$ & 14 & 14 \\
\hline
\end{tabular}

HAC standard errors and covariance. Significant at * $10 \%$; ** 5\%; *** $1 \%$.

Figure A.2 illustrates that financial intermediation and, to a lesser extent, postal services, do show more persistent deviations from the steady state. We can only speculate about the explanations behind the increased mismatch in these two sectors. The outward shift of the steady-state curve in financial services might be related to increasing automation and digitalisation of bank and insurance services in recent years. Administrative tasks have been automated and bank transactions are increasingly settled digitally, which reduces the need for an extensive network of bank branches (UWV, 2014). These employment trends mainly affect the medium skilled. At the same time, employment in financial services is increasing in areas such as auditing, data science (i.e. Big data), and supervisions. These occupations usually require 
higher education. The increasing mismatch in postal activities might be related to the effects of the liberalisation of the postal market that have begun to mature and increasing digitalisation of postal services.

Figure A.2 Steady-state Beveridge curve on the sector level

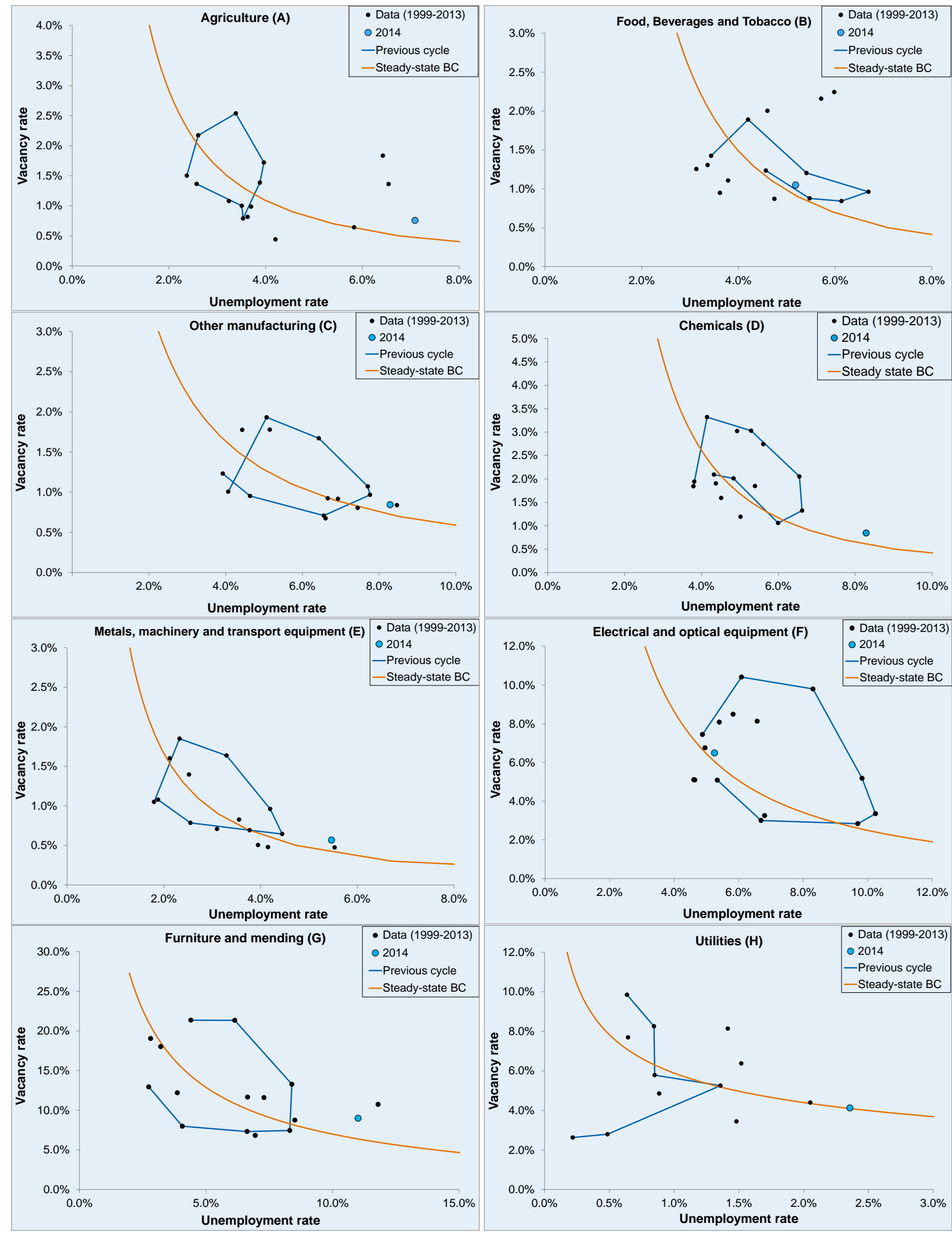


(Figure A.2 continued)

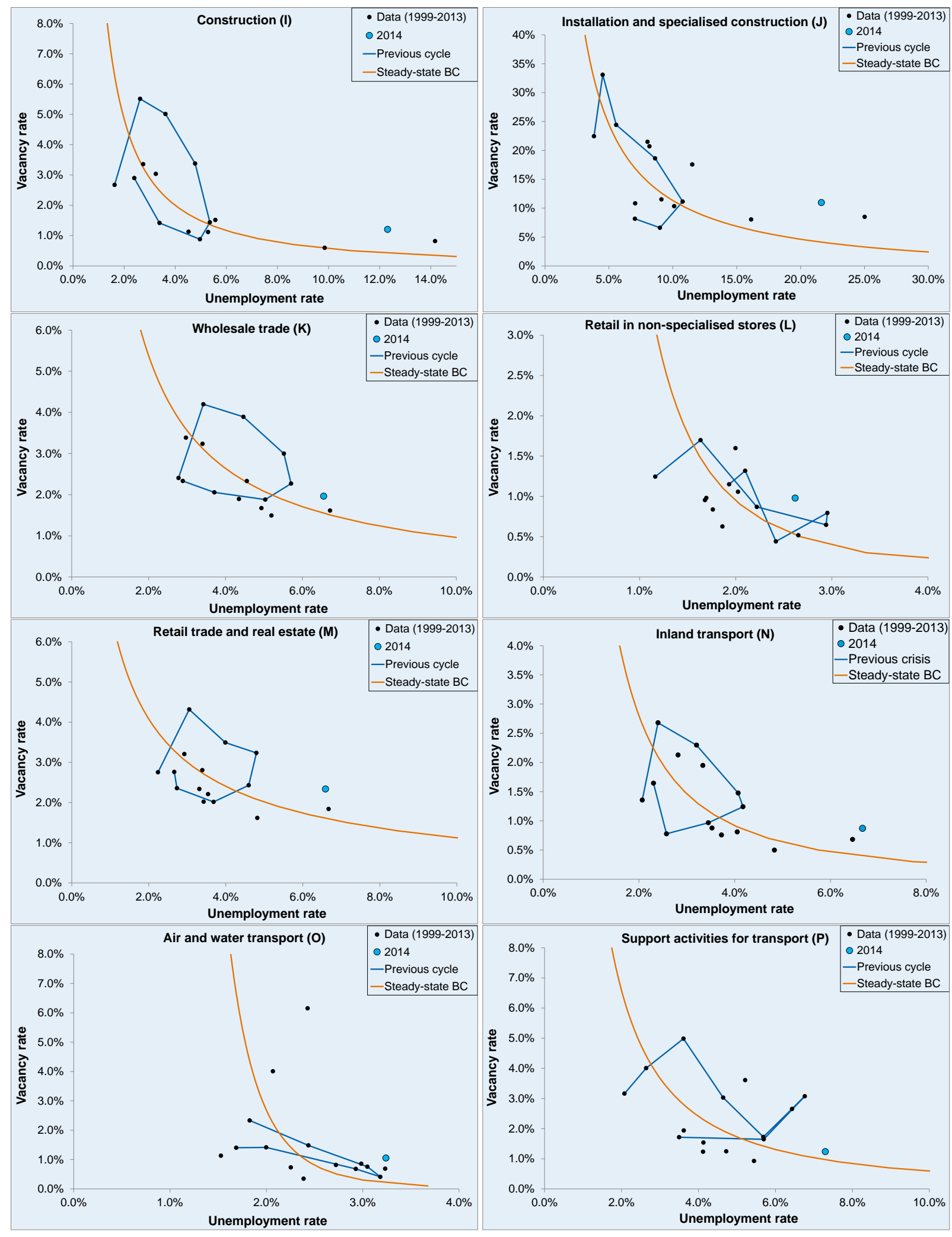


(Figure A.2 continued)

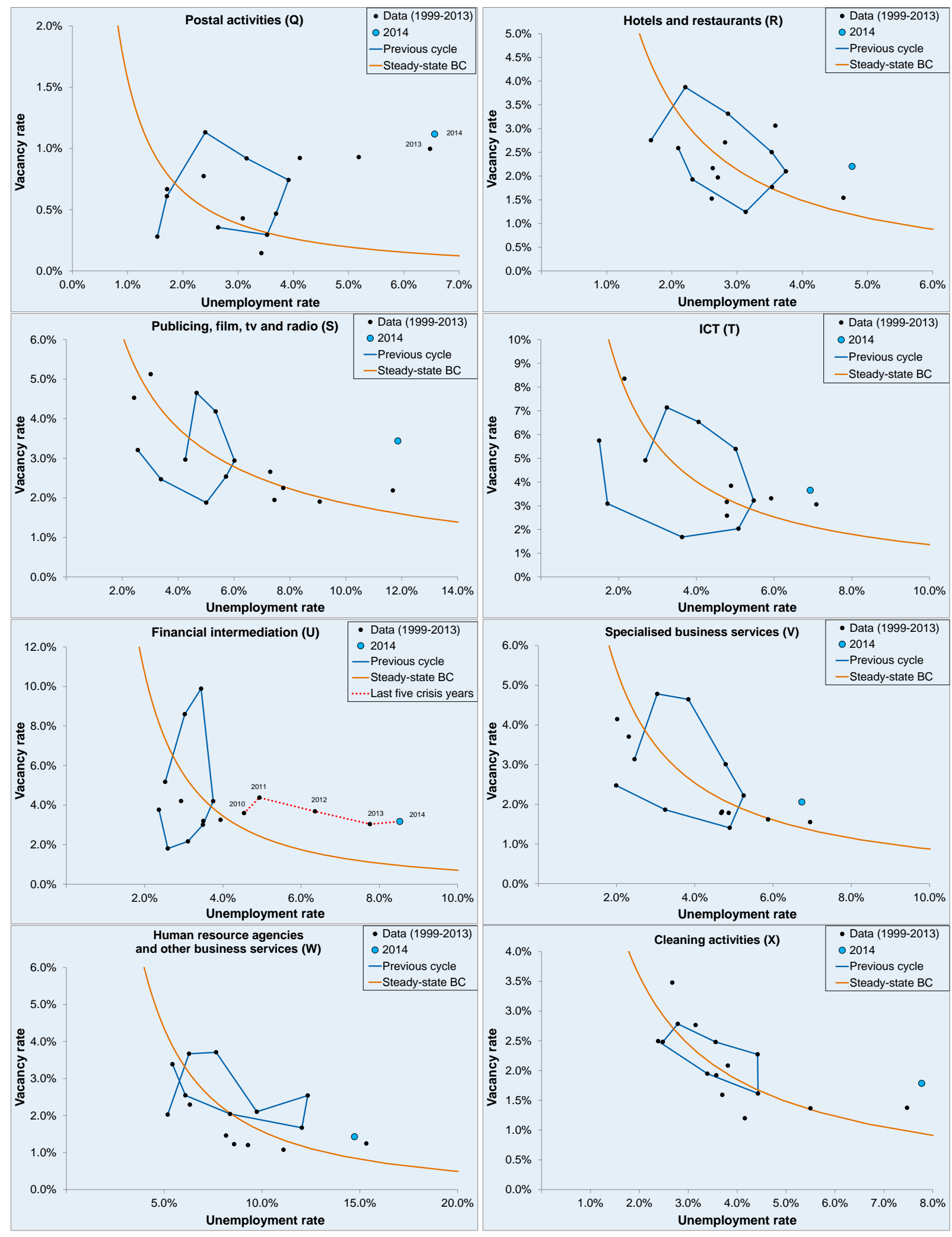


(Figure A.2 continued)

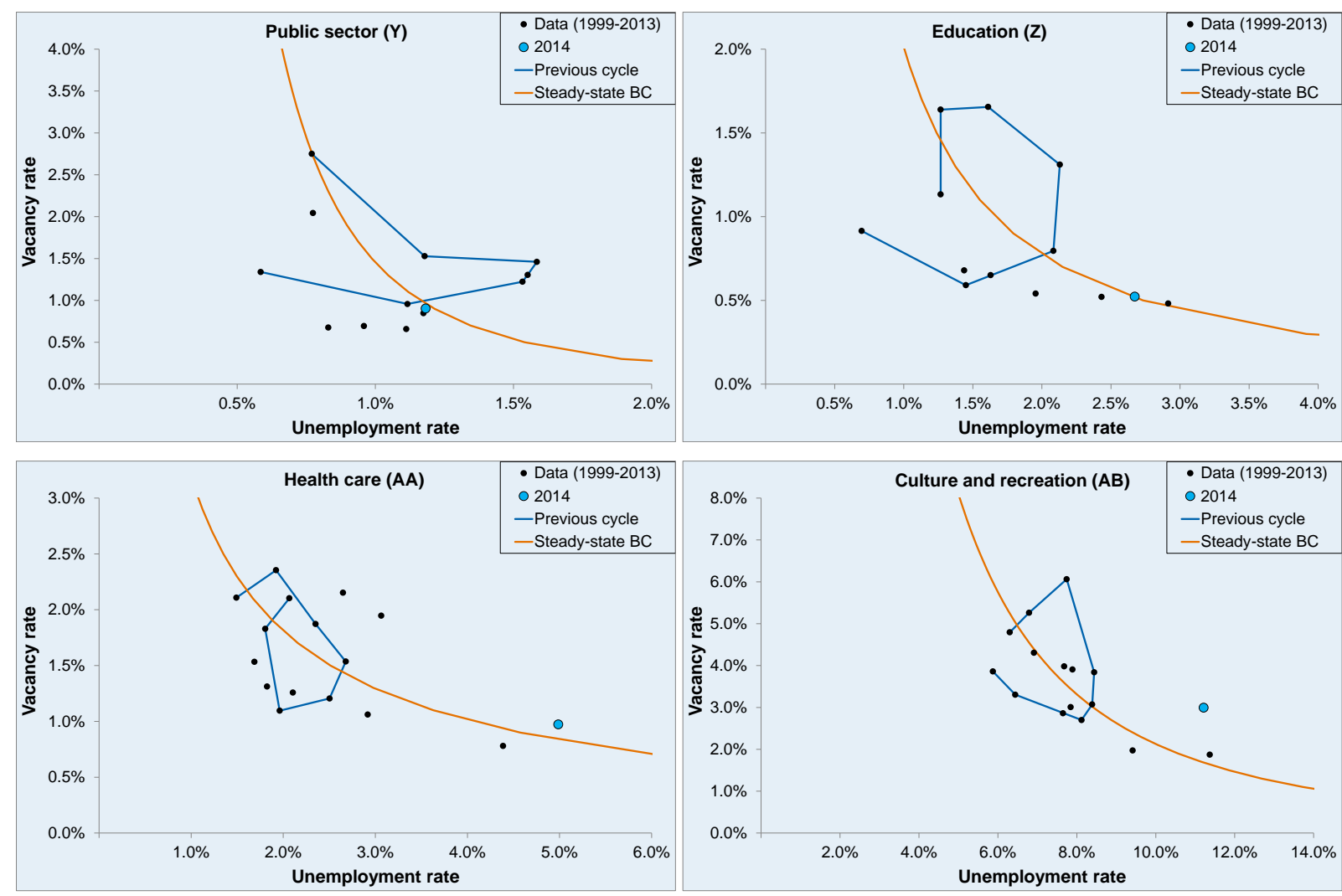

Source: own calculations based on data from UWV and Statistics Netherlands.

\section{A.9 Panel estimations}

The estimation of equation (16) is based industry vacancy data from Statistics Netherlands. As we lack data on unemployment and hirings at the sector level, we use data on unemployment benefits recipients and the number of recipients who exit benefit schemes. The results show that, when controlling for time and sector-specific effects, the elasticity of labour market tightness has a significant and positive effect on the number of exits as a fraction of unemployment benefit recipients. Thus, if the number of vacancies increases by 1 percentage point, the number of recipients exiting benefits increases by 0.17 percentage points. Looking at the sector-specific matching efficiency parameters, we can for instance observe that within the construction sector (I), the number of recipients exiting benefits is 1.5 times higher than the geometric mean, whereas of recipients exiting benefits in financial intermediation amounts to 0.6 times the average (this can be obtained by taking the exponent of the sector-specific effects). 
Table A.3 Linear panel estimation results

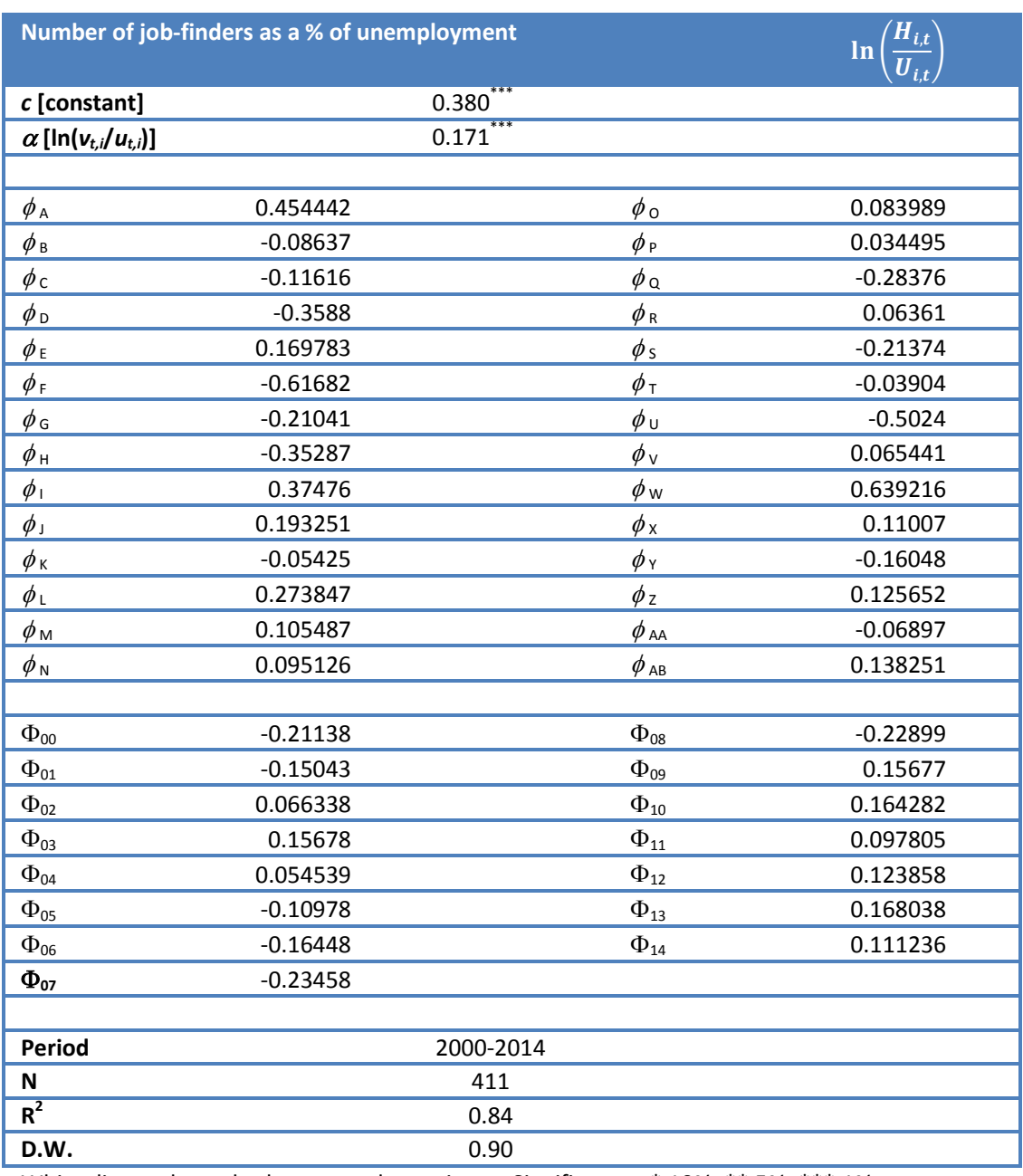

White diagonal standard errors and covariance. Significant at * $10 \% ;{ }^{* *} 5 \% ;{ }^{* * *} 1 \%$. 


\section{A.10 Miscellaneous}

Figure A.3 Labour market tightness (v/u-ratios) on the industry level

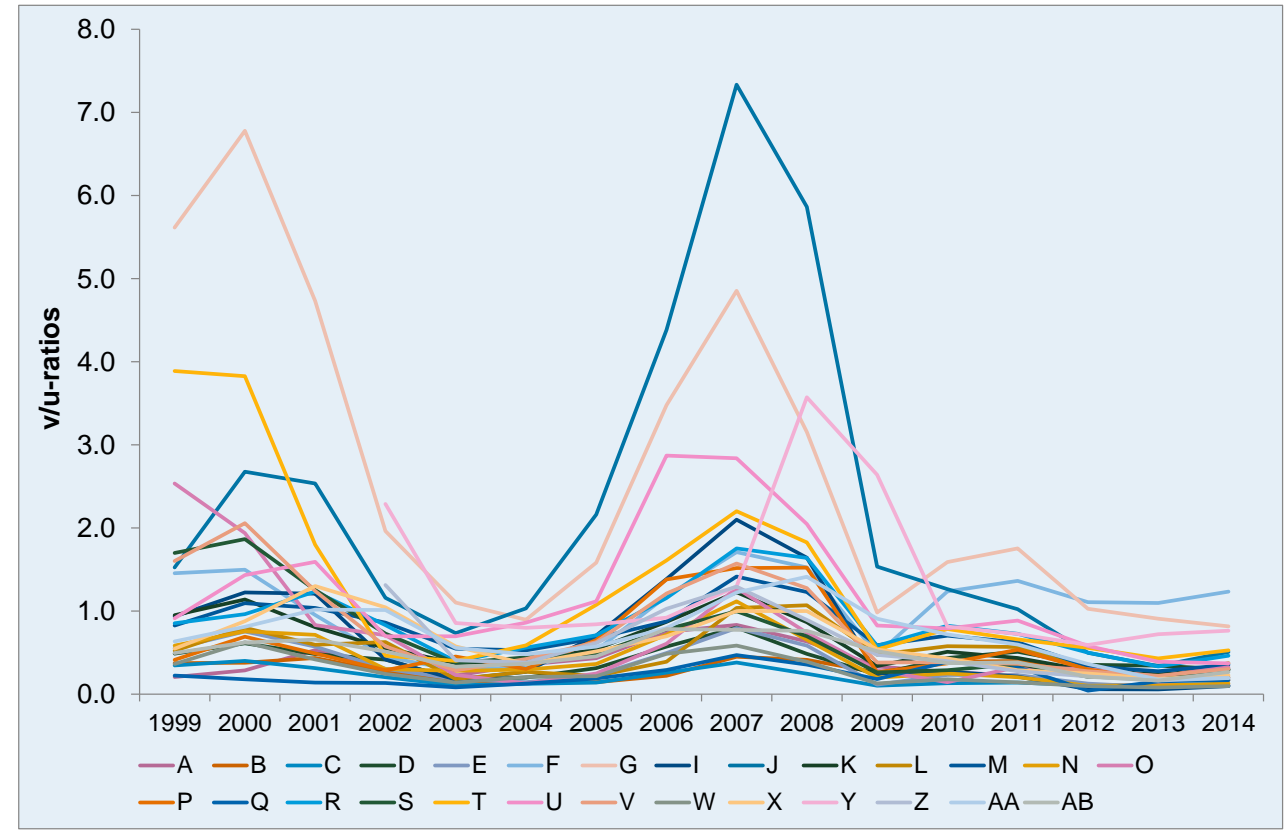

Source: Statistics Netherlands and UWV.

Figure A.4 Unemployment and steady-state unemployment

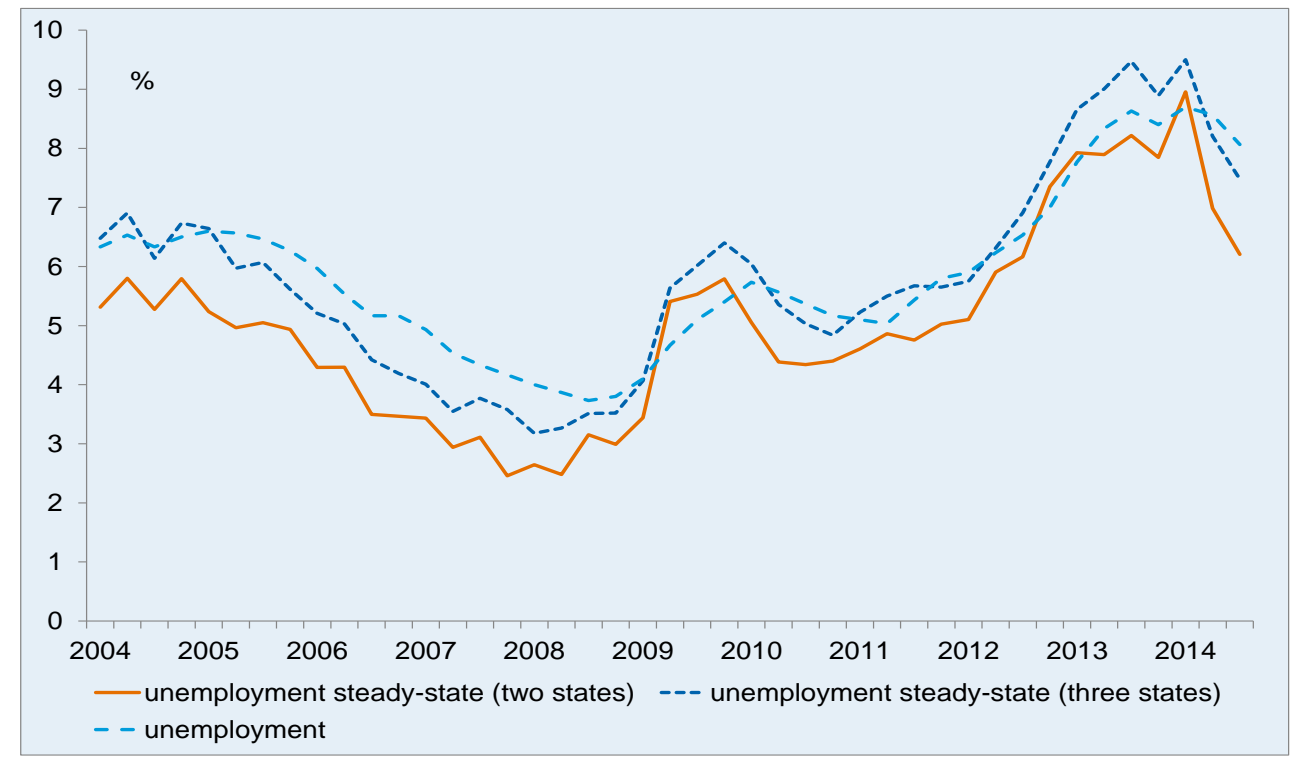


Figure A.5 Vacancy shares of sectors

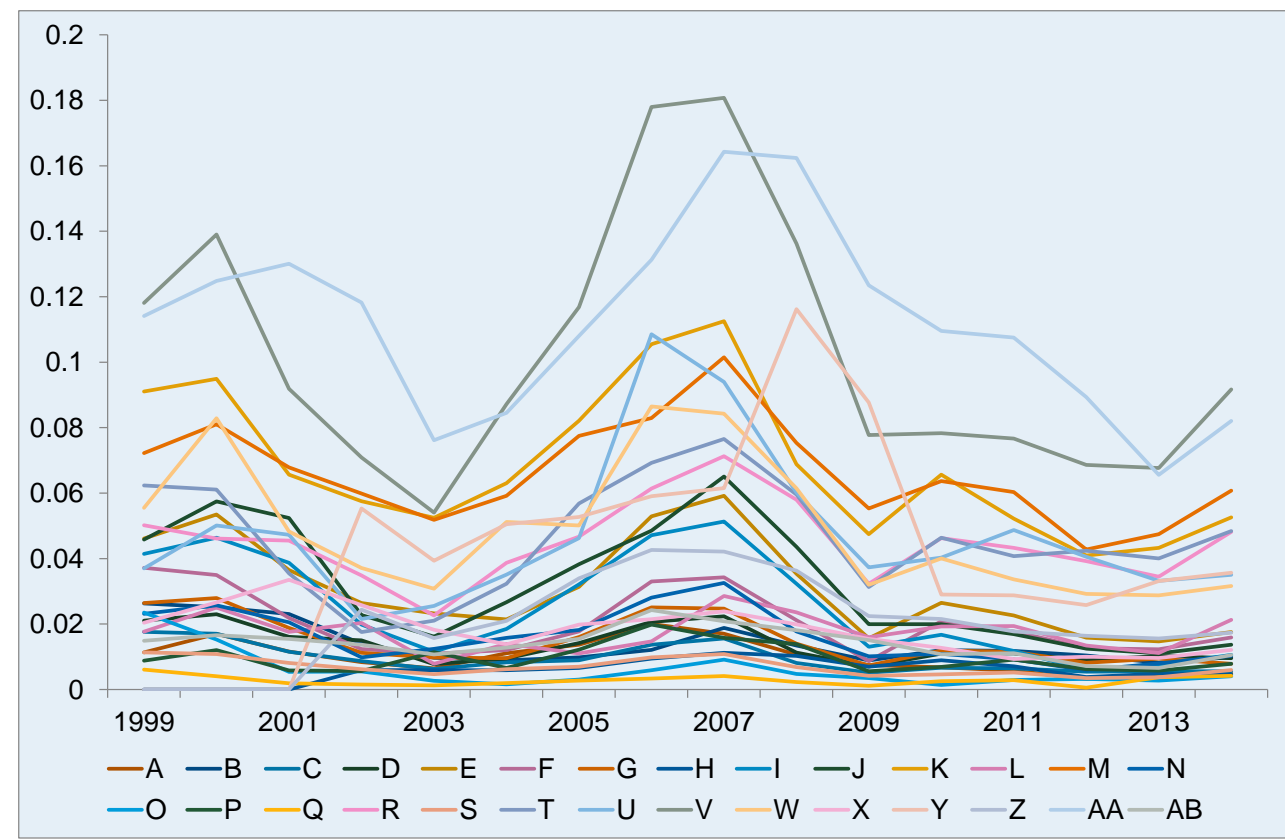



Publisher:

CPB Netherlands Bureau for Economic Policy Analysis

P.O. Box $80510 \mid 2508$ GM The Hague

$\mathrm{T}(070) 3383380$

February 2015 | ISBN 978-90-5833-680-4 